\title{
Magnetic Nanocomposites Containing Low and Medium-Molecular Weight Chitosan for Dye Adsorption: Hydrophilic Property Versus Functional Groups
}

\section{Masouma Mirzai}

Bu-Ali Sina University: Bu Ali Sina University

Simin Asadabadi ( $\square$ s.asadabadi@basu.ac.ir)

Bu-Ali Sina University: Bu Ali Sina University https://orcid.org/0000-0001-8992-6894

\section{Research Article}

Keywords: Chitosan molecular weight, Magnetic nanocomposites, DTPA, Graphene oxide, Basic blue 41, Central Composite Design

Posted Date: July 8th, 2021

DOl: https://doi.org/10.21203/rs.3.rs-684636/v1

License: (c) (1) This work is licensed under a Creative Commons Attribution 4.0 International License. Read Full License

Version of Record: A version of this preprint was published at Journal of Polymers and the Environment on October 4th, 2021. See the published version at https://doi.org/10.1007/s10924-021-02300-5. 


\title{
Magnetic Nanocomposites Containing Low and Medium-Molecular Weight Chitosan for Dye Adsorption: Hydrophilic property versus functional groups
}

\author{
Masouma Mirzai, Simin Asadabadi* \\ Department of Applied Chemistry, Faculty of Chemistry, Bu-Ali Sina University, Hamedan \\ 6517838695, Iran
}

Tel: +988138282807

Fax: +98 8138380709

*Corresponding author: (Dr. Simin Asadabadi), E-mail address: s.asadabadi@basu.ac.ir

Corresponding author's ORCID ID: 0000-0001-8992-6894

\begin{abstract}
The azo dye removal from polluted water is vital from a sustainable viewpoint. In this study, we investigated the influence of chitosan molecular weight on the adsorptive removal of basic blue 41. For preparing nanocomposite containing medium-molecular weight chitosan $(\mathrm{NC}(\mathrm{M})$ ), cross-linking of chitosan was done using diethylenetriaminepentaacetic acid, silica-modified magnetite nanoparticles and graphene oxide. Techniques including FT-IR, XRD, FESEM, TGA/DTG, VSM and $\mathrm{N}_{2}$ adsorption/desorption isotherm were applied for characterization of $\mathrm{NC}(\mathrm{M})$. The adsorption behavior of synthesized $\mathrm{NC}(\mathrm{M})$ was compared with as-prepared adsorbent containing low-molecular weight chitosan (NC(L)) (Asadabadi 2021). The experimental design was carried out using the Central Composite Design. The effect of initial $\mathrm{pH}$, temperature and adsorbent concentration on the percentage of dye removal were examined and the optimum values of variables were determined. Despite $\mathrm{NC}(\mathrm{M})$ which had maximum $31 \%$ dye removal, $\mathrm{NC}(\mathrm{L})$ led to approximately $95 \%$ adsorptive removal at optimum conditions. An increase in the monomer number of chitosan caused to reduce hydrophilic property of $\mathrm{NC}(\mathrm{M})$, which in turn resulted in a repulsion force between adsorbent and dye. However, H-bonding, coulumbic attraction and pi-stacking interactions contributed in the adsorption mechanism of NC(L). The kinetics study showed that about 30 min necessitated reaching the equilibrium and the rate-limiting steps changed from film diffusion to intraparticle diffusion as time passed. The kinetics data were satisfactorily fitted by the modified pseudo-n-order model. The maximum adsorption capacity of $\mathrm{NC}(\mathrm{L})$ was obtained $55.87 \mathrm{mg} \cdot \mathrm{g}^{-1}$. The modified Langmuir-Freundlich isotherm was the best model to reproduce data. $\mathrm{NC}(\mathrm{L})$ was recovered seven times without dramatic changes in its adsorption efficiency.
\end{abstract}

Keywords Chitosan molecular weight; Magnetic nanocomposites; DTPA; Graphene oxide; Basic blue 41, Central Composite Design

\section{Introduction}

Remarkable increase of the demand for treated water is resulted from the fast growth of population and industrial development [1,2]. Discharging effluents of dyes from textile, leather, 
paper and cosmetics industries is one of the most concerning issues [3, 4]. Most synthetic dyes are non-biodegradable producing colored water, absorb/reflect sunlight and produce carcinogenic bio-transformed intermediates thus they imperil the aquatic and human life [5]. Azo, indigoid and anthraquinoid are the major class of dyes. Among them, azo dye molecules have a conjugated system of aromatic rings and nitrogen double bonds with strong $\pi \rightarrow \pi^{*}$ transitions in the UV-Vis region [5]. Aromatic amines can be formed because of azo bond cleavage and reduction creating severe environmental problems. Different techniques such as reverse osmosis, chemical oxidation, adsorption, coagulation, electrochemical methods and their combinations can be used for treatment of the industrial azo dyes [6-8]. Cost, efficiency, ease of operation, the amount of secondary waste and facile recovery make adsorption process as a suitable approach for effluent treatment [9]. Developing a cost-effective, biodegradable and efficient adsorbent has been a big challenge for researchers to remove dangerous azo dyes $[10,11]$. Graphene-based materials, hydrogels and bio-polymers can be utilized for dye adsorption $[12,13]$.

Chitosan (CS) is a natural polysaccharide (Poly- $\beta-(1 \rightarrow 4)-\mathrm{D}$-glucosamine with randomly distributed $\mathrm{N}$-acetyl-D-glucosamine units) can be obtained from chitin and has been considered for tackling the problem of contaminated water [14, 15]. Although this bio-polymer has abundant functional groups, its application is limited by low adsorption capacity, inadequate hydrophilicity and poor recyclability [16]. Grafting and chemical cross-linking of chitosan is considered as a route to overcome the disadvantages of raw chitosan [17-19]. For instance, using aminopolycarboxylic acid such as nitrilotriacetic acid (NTA), ethylenediaminetetraacetic acid (EDTA) and diethylenetriaminepentaacetic acid (DTPA) can improve adsorption properties of chitosan [20-22]. However, the synergism effect is restricted since there is only a single adsorption mechanism, mainly electrostatic attraction. Thus, adding a compound possessing aromatic rings to the chitosan cause to have the $\pi-\pi$ stacking and cation- $\pi$ interaction between cationic azo dye and sorbent [23]. Graphene oxide (GO) with aromatic rings are a good candidate for this purpose. GO nanosheets have functional groups of carboxyl, hydroxyl and epoxy which give GO outstanding surface characteristics and attract researchers' attention for improving the properties of chitosan [18, 24]. For example, Jiang et al. [18] synthesized a nanocomposite consisting thiol-modified chitosan and magnetic graphene oxide and used it for effective adsorption of methyl blue and crystal violet dyes. Adsorbent was successfully recycled five times.

Technology of magnetic separation is one of the reasonable approach to efficient recovery 
of chitosan. One of the best materials used for magnetization is magnetite nanoparticles $\left(\mathrm{Fe}_{3} \mathrm{O}_{4}\right)$ because of its superparamagnetic property, biocompatibility and low toxicity [25]. In many cases, surface modification of $\mathrm{Fe}_{3} \mathrm{O}_{4}$ is important for two reasons; (I) protection of magnetite from oxidation and (II) generating surface functional groups for attaching to precursors of adsorbent [26]. In 2021, Liu et al. [27] synthesized a magnetic amphiphilic chitosan-based adsorbent having benzyl groups and applied it for removing azo dyes. The presence of benzyl groups and magnetic chitosan resulted in a high adsorption because of synergism effect.

Another factor having influence on the adsorption efficiency is the molecular weight of chitosan. Commercial chitosan can be supplied in low (50-190 kDa), medium (190-310 kDa) and high-molecular weight (310-375 kDa). On the one hand, an increase in the monomer unit leads to the increase in the functional groups. On the other hand, hydrophilic property changes by molecular weight $[7,27,28]$. To show importance of functional groups and hydrophilicity, a magnetic medium-molecular weight chitosan adsorbent was prepared and used for adsorption of basic blue 41 (as an azo dye pollutant). A comparison was made with as-prepared adsorbent containing low-molecular weight chitosan [20]. Graphene oxide and DTPA were used for crosslinking of chitosan and magnetization was done by silica-modified magnetite nanoparticles. Central Composite Design based on the Response Surface Methodology was applied for design of experiments and optimization. Kinetics and equilibrium studies were performed at optimum conditions and the rate limiting steps were determined. Different kinetics and isotherm models were used for fitting the experimental data. Cyclic recovery of nanocomposite was tested in different medium in the presence of ultrasonic waves.

\section{Materials and Methods}

\section{Materials}

Basic blue 41 (BB41, known as cationic blue 41) was supplied from Alvan Sabet Company with $98 \%$ purity and was used as the contaminant. Basic blue 41 is an azo dye with the chemical formula of $\mathrm{C}_{20} \mathrm{H}_{26} \mathrm{~N}_{4} \mathrm{O}_{6} \mathrm{~S}_{2}$ (the color index of 11105). This dye allows strong transition of $\pi \rightarrow \pi^{*}$ in the UV-Vis region with maximum absorption at $508 \mathrm{~nm}$. The chemical structure and UVVis absorption spectrum of BB41 is presented in Fig. 1.

Fig. 1 Structure and UV-Vis absorption spectrum of basic blue 41 at concentration of $10.0 \mathrm{mg} \cdot \mathrm{L}^{-1}$ and $\mathrm{pH}$ of 6.5

Solutions were prepared with deionized water having electrical conductivity of $0.08 \mu \mathrm{S} \cdot \mathrm{cm}^{-}$

1. Chemicals were purchased from Sigma-Aldrich and Merck companies and used without 
further purification. Specifications of chemicals are summarized in Table 1.

Table 1 Specifications of used chemicals

\begin{tabular}{|c|c|c|c|c|}
\hline Chemicals & Chemical Formula & $\begin{array}{c}\text { Molecular } \\
\text { weight } \\
\left(\mathrm{g} \cdot \mathbf{m o l}^{-1}\right)\end{array}$ & $\begin{array}{l}\text { Purity } \\
(\%)\end{array}$ & Application \\
\hline Iron(III) chloride hexahydrate & $\mathrm{FeCl}_{3} \cdot 6 \mathrm{H}_{2} \mathrm{O}$ & 271.33 & 99 & $\begin{array}{l}\text { Synthesis } \\
\mathrm{Fe}_{3} \mathrm{O}_{4}\end{array}$ \\
\hline Sodium sulfite & $\mathrm{Na}_{2} \mathrm{SO}_{3}$ & 126.04 & 95.5 & $\begin{array}{l}\text { Synthesis of } \\
\mathrm{Fe}_{3} \mathrm{O}_{4}\end{array}$ \\
\hline Fuming hydrochloric acid & $\mathrm{HCl}$ & 36.46 & 37 & $\begin{array}{l}\text { Synthesis of } \\
\mathrm{Fe}_{3} \mathrm{O}_{4} \text {, adjusting } \\
\mathrm{pH}\end{array}$ \\
\hline Ammonium hydroxide & $\mathrm{NH}_{4} \mathrm{OH}$ & 35.04 & 28 & $\begin{array}{l}\text { Synthesis of } \\
\mathrm{Fe}_{3} \mathrm{O}_{4}\end{array}$ \\
\hline Absolute ethanol & EtOH & 46.07 & 100 & $\begin{array}{l}\text { Modification of } \\
\mathrm{Fe}_{3} \mathrm{O}_{4}\end{array}$ \\
\hline Tetraethyl orthosilicate (TEOS) & $\mathrm{SiC}_{8} \mathrm{H}_{24} \mathrm{O}_{4}$ & 208.33 & 99 & $\begin{array}{l}\text { Modification of } \\
\mathrm{Fe}_{3} \mathrm{O}_{4}\end{array}$ \\
\hline Sodium hydroxide & $\mathrm{NaOH}$ & 40.00 & 99 & $\begin{array}{l}\text { Modification of } \\
\mathrm{Fe}_{3} \mathrm{O}_{4} \text {, adjusting } \\
\mathrm{pH}\end{array}$ \\
\hline $\begin{array}{l}\text { 3-aminopropyltriethoxysilane } \\
\text { (APTES) }\end{array}$ & $\mathrm{H}_{2} \mathrm{~N}\left(\mathrm{CH}_{2}\right)_{3} \mathrm{Si}\left(\mathrm{OC}_{2} \mathrm{H}_{5}\right)_{3}$ & 221.37 & 98 & $\begin{array}{l}\text { Modification of } \\
\mathrm{Fe}_{3} \mathrm{O}_{4} @ \mathrm{SiO}_{2}\end{array}$ \\
\hline Toluene & $\mathrm{C}_{7} \mathrm{H}_{8}$ & 92.14 & 99.9 & $\begin{array}{l}\text { Modification of } \\
\mathrm{Fe}_{3} \mathrm{O}_{4} @ \mathrm{SiO}_{2}\end{array}$ \\
\hline $\begin{array}{l}\text { Low-molecular weight chitosan } \\
(\mathrm{CS}(\mathrm{L}))\end{array}$ & $\left(\mathrm{C}_{6} \mathrm{H}_{11} \mathrm{NO}_{4}\right)_{\mathrm{n}}$ & $\begin{array}{l}50 \text { to } 190 \\
\mathrm{kDa}\end{array}$ & $\begin{array}{c}75-85 \% \\
\text { deacetylated }\end{array}$ & $\begin{array}{l}\text { Synthesis of } \\
\text { nanocomposite }\end{array}$ \\
\hline $\begin{array}{l}\text { Medium-molecular } \\
\text { chitosan }(\mathrm{CS}(\mathrm{M}))\end{array}$ & $\left(\mathrm{C}_{6} \mathrm{H}_{11} \mathrm{NO}_{4}\right)_{\mathrm{n}}$ & $\begin{array}{l}190 \text { to } 310 \\
\mathrm{kDa}\end{array}$ & $\begin{array}{c}75-85 \% \\
\text { deacetylated }\end{array}$ & $\begin{array}{l}\text { Synthesis of } \\
\text { nanocomposite }\end{array}$ \\
\hline $\begin{array}{l}\text { Diethylenetriaminepentaacetic } \\
\text { acid (DTPA) }\end{array}$ & $\mathrm{C}_{14} \mathrm{H}_{23} \mathrm{~N}_{3} \mathrm{O}_{10}$ & 393.35 & 99 & $\begin{array}{l}\text { Synthesis of } \\
\text { nanocomposite }\end{array}$ \\
\hline Sulfuric acid & $\mathrm{H}_{2} \mathrm{SO}_{4}$ & 98.08 & 98 & $\begin{array}{l}\text { Synthesis of } \\
\text { graphene oxide }\end{array}$ \\
\hline Orthophosphoric acid & $\mathrm{H}_{3} \mathrm{PO}_{4}$ & 98.00 & 85 & $\begin{array}{l}\text { Synthesis of } \\
\text { graphene oxide }\end{array}$ \\
\hline Graphite powder & $\mathrm{C}$ & - & - & $\begin{array}{l}\text { Synthesis of } \\
\text { graphene oxide }\end{array}$ \\
\hline Potassium permanganate & $\mathrm{KMnO}_{4}$ & 158.03 & 99 & $\begin{array}{l}\text { Synthesis of } \\
\text { graphene oxide }\end{array}$ \\
\hline Hydrogen peroxide & $\mathrm{H}_{2} \mathrm{O}_{2}$ & 34.01 & 30 & $\begin{array}{l}\text { Synthesis of } \\
\text { graphene oxide }\end{array}$ \\
\hline n-hexane & $\mathrm{C}_{6} \mathrm{H}_{14}$ & 86.18 & 96 & Solvent \\
\hline N-hydroxysuccinimide (NHS) & $\mathrm{C}_{4} \mathrm{H}_{5} \mathrm{NO}_{3}$ & 115.09 & 99 & $\begin{array}{l}\text { Activation of } \\
\text { carboxyl group }\end{array}$ \\
\hline $\begin{array}{l}\text { N,N'-dicyclohexylcarbodiimide } \\
\text { (DCC) }\end{array}$ & $\mathrm{C}_{13} \mathrm{H}_{22} \mathrm{~N}_{2}$ & 206.33 & 99 & $\begin{array}{l}\text { Activation of } \\
\text { carboxyl group }\end{array}$ \\
\hline $\begin{array}{l}\text { N,N-dimethylformamide } \\
\text { (DMF) }\end{array}$ & $\mathrm{C}_{3} \mathrm{H}_{7} \mathrm{NO}$ & 73.09 & 99.8 & Solvent \\
\hline Acetic acid & $\mathrm{CH}_{3} \mathrm{COOH}$ & 60.05 & 99.8 & Solvent \\
\hline $\begin{array}{l}\text { Sodium dihydrogen phosphate } \\
\text { monohydrate }\end{array}$ & $\mathrm{NaH}_{2} \mathrm{PO}_{4} \cdot \mathrm{H}_{2} \mathrm{O}$ & 137.99 & 98 & $\begin{array}{l}\text { Buffer } \\
\text { preparation }\end{array}$ \\
\hline
\end{tabular}

\section{Preparation of Nanocomposites}

Silica-modified magnetite, low or medium-molecular weight chitosan (CS(L) and CS(M), respectively), graphene oxide (GO) and diethylenetriaminepentaacetic acid (DTPA) were the 
components of nanocomposites.

The procedures for synthesis of $\mathrm{Fe}_{3} \mathrm{O}_{4}, \quad \mathrm{Fe}_{3} \mathrm{O}_{4} @ \mathrm{SiO}_{2}$, modified core-shell $\left(\mathrm{Fe}_{3} \mathrm{O}_{4} @ \mathrm{SiO}_{2} @ \mathrm{APTES}\right), \mathrm{GO}$ and DTPA-CS(L) and the nanocomposite with low-molecular weight chitosan (denoted as $\mathrm{NC}(\mathrm{L})$ ) were described in detail in our previous study [20]. Briefly, magnetite nanoparticles $\left(\mathrm{Fe}_{3} \mathrm{O}_{4}\right)$ were prepared using acidic solution of $\mathrm{FeCl}_{3}(18.8 \mathrm{~mL}, 2.0$ $\left.\mathrm{mol} \cdot \mathrm{L}^{-1}\right), \mathrm{Na}_{2} \mathrm{SO}_{3}$ solution $\left(12.5 \mathrm{~mL}, 1.0 \mathrm{~mol} \cdot \mathrm{L}^{-1}\right)$ and deionized water $(18.8 \mathrm{~mL})$. The mixture was quickly poured into $\mathrm{NH}_{4} \mathrm{OH}$ solution $\left(500.0 \mathrm{~mL}, 0.85 \mathrm{~mol} \cdot \mathrm{L}^{-1}\right.$ ) and stirred. $\mathrm{Fe}_{3} \mathrm{O}_{4}$ nanoparticles were obtained after $30 \mathrm{~min}$, washed out with deionized water and ethanol and dried at $25.0{ }^{\circ} \mathrm{C}$ overnight [29]. Stöber method was used for modification of magnetite [30]. After mixing of absolute ethanol $(160.0 \mathrm{~mL})$, deionized water $(40.0 \mathrm{~mL})$ and $\mathrm{Fe}_{3} \mathrm{O}_{4}(2.0000 \mathrm{~g})$ in ultrasonic bath, concentrated $\mathrm{NH}_{4} \mathrm{OH}$ solution $\left(5.0 \mathrm{~mL}, 14.82 \mathrm{~mol} \cdot \mathrm{L}^{-1}\right)$ was promptly was added. TEOS $(5.0 \mathrm{~mL})$ was poured into the mixture very slowly and stirred at room temperature for $24 \mathrm{~h}$. The particles of $\mathrm{Fe}_{3} \mathrm{O}_{4} @ \mathrm{SiO}_{2}$ were rinsed with deionized water and ethanol and dried at room temperature for $12 \mathrm{~h}$. The modified core $(1.0000 \mathrm{~g})$ was added into toluene $(60.0 \mathrm{~mL})$ and APTES $(1.0 \mathrm{~mL})$ was slowly poured into the vessel of reaction placed in the ultrasonic bath for $2 \mathrm{~h}$. The mixture was refluxed for $24 \mathrm{~h}$ under temperature of $110.0{ }^{\circ} \mathrm{C}$. The product $\left(\mathrm{Fe}_{3} \mathrm{O}_{4} @ \mathrm{SiO}_{2} @ \mathrm{APTES}\right)$ was washed out by n-hexane and ethanol, successively, and dried at room temperature [31]. For preparing GO, a cooled mixture of graphite $(0.5000 \mathrm{~g}), \mathrm{H}_{2} \mathrm{SO}_{4}$ and $\mathrm{H}_{3} \mathrm{PO}_{4}$ (8:2 volume ratio) was treated with $\mathrm{KMnO}_{4}$ (3.0000 g). After mixing, the reagents were transferred to the oil bath $\left(65.0^{\circ} \mathrm{C}\right)$ for $12 \mathrm{~h}$. After cooling the mixture, deionized water $(220.0$ $\mathrm{mL})$ and $\mathrm{H}_{2} \mathrm{O}_{2}(3.0 \mathrm{~mL}$ of $30 \% \mathrm{w} / \mathrm{w})$ were added and sonicated for $30 \mathrm{~min}$. GO nanosheets were washed out by $\mathrm{HCl}(100.0 \mathrm{~mL}, 30 \% \mathrm{w} / \mathrm{w})$, deionized water $(100.0 \mathrm{~mL})$ and ethanol, sequentially. N-hexane was used for coagulating GO sheets. The product was dried at $40.0{ }^{\circ} \mathrm{C}$ [32]. Low or medium-molecular weight chitosan was modified by DTPA. In this regard, 0.7000 g CS(L or M) were dissolved in acetic acid $(75.0 \mathrm{~mL}, 2.0 \% \mathrm{v} / \mathrm{v})$. Also, $3.6600 \mathrm{~g}$ DTPA and $0.4000 \mathrm{~g}$ N-hydroxysuccinimide (NHS) were dissolved in $\mathrm{NH}_{4} \mathrm{OH}(2.0 \mathrm{~mL}, 28 \% \mathrm{w} / \mathrm{w})$. Two solutions were slowly poured into the mixture of N,N-dimethylformamide (DMF, $50.0 \mathrm{ml}$ ) and N,N'-dicyclohexylcarbodiimide (DCC, $2.6200 \mathrm{~g}$ ) placed in ice bath. Low temperature was crucial to prevent carboxylate anion formation. After mixing, temperature of mixture was set at $60.0{ }^{\circ} \mathrm{C}$ and it was stirred for $12 \mathrm{~h}$. DTPA-CS(L) and DTPT-(M) were washed out with deionized water and dried at $45.0^{\circ} \mathrm{C}$ for $12 \mathrm{~h}$.

Nanocomposites having low and medium-molecular weight chitosan (NC(L) and $\mathrm{NC}(\mathrm{M}))$ were synthesized by adding $\mathrm{Fe}_{3} \mathrm{O}_{4} @ \mathrm{SiO}_{2} @$ APTES (0.5700 g), GO (0.6000 g), DCC (1.5000 
g), NHS (0.2400 g) and DTPA-CS(L) or DTPA-CS(M) (0.3700 g) into DMF (50.0 mL). Mixed materials were heated up to $60.0^{\circ} \mathrm{C}$ for $24 \mathrm{~h}$. Temperature and time of reaction were optimized by trial. The products were rinsed with DMF and ethanol and dried at $25.0{ }^{\circ} \mathrm{C}$ for $12 \mathrm{~h}$.

\section{Instrumentation}

FT-IR spectra were obtained by the Fourier Transform Infrared spectrophotometer (FT-IR, PerkinElmer Spectrum 65). Philips PW1730 was used for having XRD patterns. The field emission scanning electron microscopy was performed by TESCAN MIRA 3. Thermal decomposition data was obtained using gravimetric analysis (TA SDT Q600, at argon atmosphere). The Meghnatis Daghigh Kavir was used for obtaining the magnetic property of the composites. $\mathrm{N}_{2}$ adsorption/desorption isotherm was obtained by BEL BELSORP MINI II. The UV-Vis spectrophotometry was done using Jasco V-630.

\section{Modeling}

In general, in multiple regression model, response $(R)$ can be related to $f$ predictor variables $\left(x_{\mathrm{i}}\right)$ with considering interaction terms according to Eq. (1):

$$
R=\beta_{0}+\sum_{\mathrm{i}=1}^{f} \beta_{\mathrm{i}} x_{\mathrm{i}}+\sum_{\mathrm{i}=1}^{f} \beta_{\mathrm{ii}} x_{\mathrm{i}}^{2}+\sum_{\mathrm{i}=1}^{f-1} \sum_{\mathrm{j}=2}^{f} \beta_{\mathrm{ij}} x_{\mathrm{i}} x_{\mathrm{j}}+\varepsilon
$$

where, $\beta_{0}$ is the intercept, $\beta_{\mathrm{i}}$ is the regression coefficient for the linear terms, $\beta_{\mathrm{ii}}$ corresponds to the quadratic terms and $\beta_{\mathrm{ij}}$ shows the interactions terms. Also, $\varepsilon$ is a statistical error. It is assumed that error has a normal distribution.

Hypothesis testing in regression is helpful for measuring the adequacy of the model and determining the important predictors. In this regard, the null $\left(H_{0}\right)$ and alternative hypothesizes $\left(H_{\mathrm{a}}\right)$ are:

$$
\begin{aligned}
& H_{0}: \beta_{\mathrm{i}}=\beta_{\mathrm{ii}}=\beta_{\mathrm{jj}}=\beta_{\mathrm{ij}}=0 \\
& H_{\mathrm{a}}: \beta_{\mathrm{i}} \neq 0 \text { and/or } \beta_{\mathrm{ii}} \neq 0 \text { and/or } \beta_{\mathrm{ij}} \neq 0
\end{aligned}
$$

Rejection of $H_{0}$ implies that at least one of the predictors has significant contribution to the model. To conduct hypothesis, error must have normal distribution with zero mean and constant variance.

Analysis of variance (ANOVA) is used as a test procedure for testing $H_{0}$ at $95 \%$ confidence interval (with significant level of $\alpha=0.05$ ). $F$ statistic is calculated by Eq. (3): 


$$
F_{0}=\frac{\mathrm{SS}_{\text {model }} / k}{\mathrm{SS}_{\text {residual }} /(n-p)}
$$

in which, $\mathrm{SS}_{\text {model }}$ and $\mathrm{SS}_{\text {residual }}$ are sum of square for model and residual, respectively, $n$ is the number of observation, $k$ is number of linear, quadratic and interaction terms in the model and $p(=k+1)$ is the number of all terms including the intercept.

If $F_{0}$ is greater than $F_{a, k, n-k-1}$, then $H_{0}$ is rejected. Alternatively, when the $p$-value of model is less than $\alpha, H_{0}$ is rejected.

There are some statistics in order to select and evaluate the adequacy of the model. Table 2 contains the formula for residual, sum of squares of residual, model and total ( $\mathrm{SS}_{\text {residual }}, \mathrm{SS}_{\text {model }}$, $\mathrm{SS}_{\text {total }}$ ), prediction error sum of squares (PRESS), coefficient of determination $\left(R^{2}\right)$, adjusted coefficient of determination $\left(R_{\text {Adj. }}^{2}\right)$, predicted coefficient of determination $\left(R_{\text {Pred. }}^{2}\right)$, standard deviation $(s)$, coefficient of variation (C.V.\%), adequate precision (A.P.) and root mean square error (RMSE) [33].

Table 2 Statistic for testing the adequacy of model

\begin{tabular}{|c|c|}
\hline Statistic & Formula \\
\hline Residual & residual $=R_{\text {exp }, \mathrm{i}}-R_{\text {cal }, \mathrm{i}}$ \\
\hline Sum of squares of residual & $\mathrm{SS}_{\text {residual }}=\sum_{\mathrm{i}=1}^{n}\left(R_{\text {exp }, \mathrm{i}}-R_{\text {cal, } \mathrm{i}}\right)^{2}$ \\
\hline Sum of squares of model & $\mathrm{SS}_{\text {model }}=\mathrm{SS}_{\text {total }}-\mathrm{SS}_{\text {residual }}$ \\
\hline Sum of squares of total & $\mathrm{SS}_{\text {total }}=\sum_{\mathrm{i}=1}^{n}\left(R_{\mathrm{exp}, \mathrm{i}}-\bar{R}\right)^{2}$ \\
\hline Prediction error sum of squares & $\operatorname{PRESS}=\sum_{\mathrm{i}=1}^{n}\left(R_{\mathrm{exp}, \mathrm{i}}-R_{\mathrm{cal},(\mathrm{i})}\right)^{2}$ \\
\hline Coefficient of determination & $R^{2}=1-\frac{\mathrm{SS}_{\text {residual }}}{\left(\mathrm{SS}_{\text {model }}+\mathrm{SS}_{\text {residual }}\right)}$ \\
\hline Adjusted coefficient of determination & $R_{\text {Adj. }}^{2}=1-\frac{\mathrm{SS}_{\text {residual }} /(n-p)}{\left(\mathrm{SS}_{\text {model }}+\mathrm{SS}_{\text {residual }}\right) /(n-1)}$ \\
\hline Predicted coefficient of determination & $R_{\text {Pred. }}^{2}=1-\frac{\text { PRESS }}{\left(\mathrm{SS}_{\text {model }}+\mathrm{SS}_{\text {residual }}\right) /(n-1)}$ \\
\hline Standard deviation & $s=\sqrt{\frac{\sum_{\mathrm{i}=1}^{\mathrm{n}}\left(R_{\text {exp }, \mathrm{i}}-\bar{R}\right)^{2}}{\mathrm{n}-1}}$ \\
\hline Coefficient of variation & C.V. $=\frac{s}{\bar{R}} \times 100 \%$ \\
\hline Adequate precision & A.P. $=\frac{\text { Signal }}{\text { Noise }}$ \\
\hline
\end{tabular}


Root mean square error

$$
\text { RMSE }=\sqrt{\frac{\text { SS }_{\text {residual }}}{n-p}}
$$

$R_{\text {exp,i }}$ and $R_{\text {cal,i }}$ are experimental (observed) and calculated (predicted) responses, respectively. SS stands for sum of squares. Also, $\bar{R}$ represents the mean of response and PRESS shows how well the model fits every points in the design.

\section{Design of Experiments}

Central Composite Design (CCD) based on the Response Surface Methodology was used for design of experiments. The selected factors were initial $\mathrm{pH}$, temperature $(T)$ and nanocomposite concentration $\left(C_{\mathrm{NC}}\right)$. The initial concentration of BB41 was kept constant $\left(C_{0}=\right.$ $\left.10.0 \mathrm{mg} \cdot \mathrm{L}^{-1}, 10.0 \mathrm{ml}\right)$. The percentage of dye removal $(R e \%)$ was selected as the response of the design and obtained by Eq. (4) [34]:

$$
R e \%=\frac{\left(C_{0}-C_{\text {res. }}\right)}{C_{0}} \times 100 \%
$$

where $C_{\text {res. }}$ was the dye residual concentration.

Five levels were considered for each factor in CCD. The factorial, axial and center points were coded as “ \pm 1 ”, “ 0 ”, and " $\pm \alpha$ ”, respectively. The levels of factors are presented in Table 3.

Table 3 Levels of factors used in CCD

\begin{tabular}{lccccc}
\hline \multirow{5}{*}{ Factor } & \multicolumn{5}{c}{ Level } \\
\cline { 2 - 6 } & $\boldsymbol{- \alpha}$ & $\mathbf{- 1}$ & $\mathbf{0}$ & $\mathbf{+ 1}$ & $\boldsymbol{+} \boldsymbol{\alpha}$ \\
\hline $\mathrm{pH}$ & 4.14 & 5.50 & 7.50 & 9.50 & 10.86 \\
$T\left({ }^{\circ} \mathrm{C}\right)$ & 17.8 & 28.0 & 43.6 & 58.0 & 68.2 \\
$C_{\mathrm{NC}}\left(\mathrm{g} \cdot \mathrm{L}^{-1}\right)$ & 0.12 & 0.60 & 1.30 & 2.00 & 2.48 \\
\hline
\end{tabular}

Synthesized nanocomposites (NC(L) and NC(M)) were used for each set of design. Twenty experiments were carried out in order to identify the effect of factors on the response and interactions between factors along with optimum conditions. The contacting time was $60 \mathrm{~min}$ for all runs.

\section{Kinetics Experiments}

The results of CCD optimization were used for kinetics and equilibrium studies. In this regard, $\mathrm{pH}$ and temperature of solutions were set at 9.02 and $47.1{ }^{\circ} \mathrm{C}$, respectively. Then 0.0198 $\mathrm{g}$ of nanocomposite was added into the solution. Then, each mixture was shaken at $150 \mathrm{rpm}$. Initial concentration of BB41 were 8.0, 15.0, and $30.0 \mathrm{mg} \cdot \mathrm{L}^{-1}(10.0 \mathrm{ml})$ for kinetics experiments. The residual concentration $\left(C_{\mathrm{t}}\right)$ was obtained using the UV-Vis spectrophotometer (at $\lambda_{\max }=608 \mathrm{~nm}$ ) at different time intervals and the amount of BB41 adsorbed per unit mass 
of nanocomposite $\left(q_{\mathrm{t}}\right.$ as $\left.\mathrm{mg} \cdot \mathrm{g}^{-1}\right)$ was calculated by Eq. (5) [35]:

$$
q_{\mathrm{t}}=\frac{V\left(C_{0}-C_{\mathrm{t}}\right)}{m}
$$

in which, $V$ was the volume of dye solution (as L) and $m$ was the nanocomposite mass (as $\mathrm{g}$ ).

The maximum standard deviation was calculated $\pm 0.4 \mathrm{mg} \cdot \mathrm{g}^{-1}$ for $q_{\mathrm{t}}$ by repeating the experiments three times.

\section{Equilibrium Experiments}

Dye concentrations ranging from 50.0 to $600.0 \mathrm{mg} \cdot \mathrm{L}^{-1}$ were used for doing equilibrium experiments. The amount of $0.0198 \mathrm{~g}$ nanocomposite was dispersed in $10.0 \mathrm{ml}$ of dye solutions with $\mathrm{pH}$ of 9.02 and temperature of $47.1{ }^{\circ} \mathrm{C}$. All mixtures were placed into the water bath shaker for $4 \mathrm{~h}$ (at $150 \mathrm{rpm}$ ). According to Eq. (6), the equilibrium concentrations $\left(C_{\mathrm{e}}\right)$ were used for calculating the amount of adsorbed dye per unit mass of nanocomposite at equilibrium $\left(q_{\mathrm{e}}\right.$ as $\left.\mathrm{mg} \cdot \mathrm{g}^{-1}\right)[34]:$

$$
q_{\mathrm{e}}=\frac{V\left(C_{0}-C_{\mathrm{e}}\right)}{m}
$$

All experiments were repeated three times and the maximum standard deviation was \pm 3.0 $\mathrm{mg} \cdot \mathrm{g}^{-1}$ for $q_{\mathrm{e}}$.

\section{Recovery of Nanocomposite}

Recovery of adsorbent had three stages. At saturation step, the amount of $0.0200 \mathrm{~g}$ of nanocomposite was added into $10.0 \mathrm{ml} \mathrm{BB} 41$ solution with concentration of $300.0 \mathrm{mg} \cdot \mathrm{L}^{-1}$. The nanocomposite was separated from solution after $24 \mathrm{~h}$ and dried. In the second stage (desorption step), the saturated nanocomposite was washed out with $10.0 \mathrm{ml}$ of different eluents including hydrochloric acid, sodium hydroxide or sodium chloride solutions $\left(0.1 \mathrm{~mol} \cdot \mathrm{L}^{-1}\right)$. The desorption step was repeated in the presence of ultrasonic waves for $5 \mathrm{~min}$. At adsorption stage, a newly prepared solution of BB41 $\left(10.0 \mathrm{mg} \cdot \mathrm{L}^{-1}, 10.0 \mathrm{ml}\right.$ at $\mathrm{pH}$ of 9.02 and temperature of 47.1 ${ }^{\circ} \mathrm{C}$ ) was contacted with $0.0198 \mathrm{~g}$ of the nanocomposite. After $10 \mathrm{~min}$ of adsorption, the nanocomposite was separated, dried and reused for the next cycle [36]. Seven desorption adsorption cycles were tested.

\section{Results and Discussion}




\section{Characterizations}

FT-IR spectra of materials used for synthesizing NC(M) are presented in Fig. 2. NC(M) spectrum had the characteristics peak of $\mathrm{Fe}_{3} \mathrm{O}_{4}, \mathrm{Fe}_{3} \mathrm{O}_{4} @ \mathrm{SiO}_{2}, \mathrm{Fe}_{3} \mathrm{O}_{4} @ \mathrm{SiO}_{2} @ A P T E S$, DTPA$\mathrm{CS}(\mathrm{M})$ and GO. Relevantly, the peaks of $\mathrm{Fe}-\mathrm{O}\left(\approx 640 \mathrm{~cm}^{-1}\right), \mathrm{Si}-\mathrm{O}\left(\approx 1088 \mathrm{~cm}^{-1}\right)$ and $\mathrm{C}-\mathrm{H}$ (2930, and $2852 \mathrm{~cm}^{-1}$ ) were observed. Cross-linking was resulted from amide formation and chemical bonding between DTPA-CS(M) and/or CS(M)-APTES portion of modified magnetite and/or CS(M)-GO and/or DTPA-APTES portion [37]. Correspondingly, the peak for $\mathrm{N}-\mathrm{H}$ (secondary amide) was overlapped with $\mathrm{O}-\mathrm{H}$ and primary amine at $3327 \mathrm{~cm}^{-1}$ [38]. A peak at $1575 \mathrm{~cm}^{-1}$ belonged to the $\mathrm{N}-\mathrm{H}$ bending vibration and $\mathrm{C}-\mathrm{N}$ (amine) had a peak at $1245 \mathrm{~cm}^{-1}$. The nanocomposite had aromatic $\mathrm{C}=\mathrm{C}$ peaks at 1627 and $1437 \mathrm{~cm}^{-1}$. However, carbonyl vibration was too low (at $\approx 1715 \mathrm{~cm}^{-1}$ ) due to the formation of amide [39].

Fig. 2 FT-IR spectra of $\mathrm{Fe}_{3} \mathrm{O}_{4}, \mathrm{Fe}_{3} \mathrm{O}_{4} @ \mathrm{SiO}_{2}, \mathrm{Fe}_{3} \mathrm{O}_{4} @ \mathrm{SiO}_{2} @ A P T E S$, GO, DTPA, CS(M), DTPA-CS(M), and $\mathrm{NC}(\mathrm{M})$

The XRD patterns are shown in Fig. 3. The peaks of $\mathrm{Fe}_{3} \mathrm{O}_{4}$ were observed at $2 \theta=30.8^{\circ}$, $36.2^{\circ}, 43.7^{\circ}, 54.1^{\circ}, 57.6^{\circ}$, and $63.4^{\circ}$ [40]. This pattern was repeated in $\mathrm{Fe}_{3} \mathrm{O}_{4} @ \mathrm{SiO}_{2}$, $\mathrm{Fe}_{3} \mathrm{O}_{4} @ \mathrm{SiO}_{2} @$ APTES and NC(M). Also, nanocomposite had patterns of DTPA-CS(M). GO peak (at $2 \theta=10.3^{\circ}$, corresponding to the interlayer spacing of $0.81 \mathrm{~nm}$ ) was not clearly observed in $\mathrm{NC}(\mathrm{M})$. However, the distinguished peak of GO was in XRD pattern of $\mathrm{NC}(\mathrm{L})$ in our previous study [20]. It could be concluded that lesser GO sheets were attached to the surface of $\mathrm{NC}(\mathrm{M})$ due to lesser hydrophilicity property of DTPA-CS(M) [7].

Fig. 3 XRD patterns of $\mathrm{Fe}_{3} \mathrm{O}_{4}, \mathrm{Fe}_{3} \mathrm{O}_{4} @ \mathrm{SiO}_{2}, \mathrm{Fe}_{3} \mathrm{O}_{4} @ \mathrm{SiO}_{2} @$ APTES, GO, DTPA-CS(M), and NC(M)

Fig. 4 shows FESEM images of $\mathrm{Fe}_{3} \mathrm{O}_{4}, \mathrm{Fe}_{3} \mathrm{O}_{4} @ \mathrm{SiO}_{2}, \mathrm{Fe}_{3} \mathrm{O}_{4} @ \mathrm{SiO}_{2} @ \mathrm{APTES}, \mathrm{GO}, \mathrm{DTPA}-$ $\mathrm{CS}(\mathrm{M})$, and $\mathrm{NC}(\mathrm{M})$. Cauliflower structure was found for $\mathrm{Fe}_{3} \mathrm{O}_{4}, \mathrm{Fe}_{3} \mathrm{O}_{4} @ \mathrm{SiO}_{2}$, and $\mathrm{Fe}_{3} \mathrm{O}_{4} @ \mathrm{SiO}_{2} @$ APTES. The average size of $\mathrm{Fe}_{3} \mathrm{O}_{4}$ nanoparticles was 34 nm, based on the size distribution histograms (Supplementary Information, Fig. S1). $\mathrm{Fe}_{3} \mathrm{O}_{4} @ \mathrm{SiO}_{2}$ and $\mathrm{Fe}_{3} \mathrm{O}_{4} @ \mathrm{SiO}_{2} @$ APTES had the average size of 56 and $83 \mathrm{~nm}$, respectively. Sheets were distinguished in FESEM image of GO. Besides, DTPA-CS(M) had polyhedron and rod structures. The morphology of $\mathrm{NC}(\mathrm{M})$ was quite complex and contained sheets, cauliflower and rod shapes similar to $\mathrm{NC}(\mathrm{L})$ [20].

Fig. 4 FESEM images of $\mathrm{Fe}_{3} \mathrm{O}_{4}, \mathrm{Fe}_{3} \mathrm{O}_{4} @ \mathrm{SiO}_{2}, \mathrm{Fe}_{3} \mathrm{O}_{4} @ \mathrm{SiO}_{2} @$ APTES, GO, DTPA-CS(M), and NC(M) 
The thermal stability of $\mathrm{Fe}_{3} \mathrm{O}_{4}, \mathrm{Fe}_{3} \mathrm{O}_{4} @ \mathrm{SiO}_{2}, \mathrm{Fe}_{3} \mathrm{O}_{4} @ \mathrm{SiO}_{2} @ \mathrm{APTES}, \mathrm{GO}, \mathrm{DTPA}-\mathrm{CS}(\mathrm{M})$, and $\mathrm{NC}(\mathrm{M})$ was evaluated by thermal gravimetric analysis (TGA). The steps in TGA plot represented mass loss due to evaporation, oxidation and decomposition. The results of TGA and its first derivative (DTG) are shown in Fig. 5 ( $a$ and b). $\mathrm{Fe}_{3} \mathrm{O}_{4}$ had a little change in mass $(9.2 \%)$ in the whole range of temperature. The mass loos were 14 and $20 \%$ for $\mathrm{Fe}_{3} \mathrm{O}_{4} @ \mathrm{SiO}_{2}$ and $\mathrm{Fe}_{3} \mathrm{O}_{4} @ \mathrm{SiO}_{2} @ \mathrm{APTES}$, respectively. The nanocomposite was approximately stable up to $254{ }^{\circ} \mathrm{C}$ being a little more stable in comparison with $\mathrm{NC}(\mathrm{L})$ which was stable up to $248{ }^{\circ} \mathrm{C}$ [20]. The first mass loss was associated to the evaporation the water adsorbed at $\mathrm{NC}(\mathrm{M})$ surface (below $100{ }^{\circ} \mathrm{C}$ ). Degradation and decomposition of organic components of APTES, DTPA, deacetylation of $\mathrm{CS}(\mathrm{M})$ and losing carbon monoxide and carbon dioxide were the major reasons for mass loss of $\mathrm{NC}(\mathrm{M})$ at temperature higher than $254{ }^{\circ} \mathrm{C}[22,41,42]$.

Fig. 5 (a) TGA and (b) DTG curves of $\mathrm{Fe}_{3} \mathrm{O}_{4}, \mathrm{Fe}_{3} \mathrm{O}_{4} @ \mathrm{SiO}_{2}, \mathrm{Fe}_{3} \mathrm{O}_{4} @ \mathrm{SiO}_{2} @ \mathrm{APTES}, \mathrm{GO}, \mathrm{DTPA}-\mathrm{CS}(\mathrm{M})$, and $\mathrm{NC}(\mathrm{M})$

The magnetization plots of magnetic materials are presented in Fig. 6. The saturation magnetization of $\mathrm{Fe}_{3} \mathrm{O}_{4}, \mathrm{Fe}_{3} \mathrm{O}_{4} @ \mathrm{SiO}_{2}, \mathrm{Fe}_{3} \mathrm{O}_{4} @ \mathrm{SiO}_{2} @ \mathrm{APTES}$ were 42, 34 and $29 \mathrm{emu} \cdot \mathrm{g}^{-1}$, respectively. The magnetic property of $\mathrm{NC}(\mathrm{M})$ decreased dramatically to $2.5 \mathrm{emu} \cdot \mathrm{g}^{-1}$. However, the value of 9.2 was obtained for $\mathrm{NC}(\mathrm{L})$ in previous study [20]. The difference between saturation magnetization of $\mathrm{NC}(\mathrm{M})$ and $\mathrm{NC}(\mathrm{L})$ showed that the layer of chitosan with more monomer of D-amino glucose caused the magnetic property declined sharply. Although this value was low for $\mathrm{NC}(\mathrm{M})$, it surprisingly had an excellent magnetic property.

Fig. 6 Magnetization measurements for $\mathrm{Fe}_{3} \mathrm{O}_{4}, \mathrm{Fe}_{3} \mathrm{O}_{4} @ \mathrm{SiO}_{2}, \mathrm{Fe}_{3} \mathrm{O}_{4} @ \mathrm{SiO}_{2} @ \mathrm{APTES}$ and $\mathrm{NC}(\mathrm{M})$

Nitrogen adsorption/desorption isotherm at $77 \mathrm{~K}$ is presented in Fig. 7 (a). NC(M) showed type IV isotherm with hysteresis loops proofing that it is a mesoporous adsorbent [43]. NC(M) exhibited $\mathrm{H} 3$ type hysteresis loop [44]. In the type $\mathrm{H} 3$ loop, there was no limiting adsorption at high relative pressure $\left(p / p_{0}\right)$. It confirmed aggregation of plate-like particles associate with slitshape pores. Estimation of pore size distribution was not reliable for type H3 loop. The Brunauer-Emmett-Teller (BET) plot is depicted in Fig. 7 (b). The specific surface area obtained by BET theory was too small $\left(3.50 \mathrm{~m}^{2} \cdot \mathrm{g}^{-1}\right)$. Actually BET theory is just applicable for finelydivided materials not for adsorbents with heterogeneous surfaces. Thus, the BET theory was not suitable for predicting the surface area and pore size of NC(M) [44].

Fig. 7 (a) $\mathrm{N}_{2}$ adsorption/desorption isotherm at $77 \mathrm{~K}$, (b) BET plot of $\mathrm{NC}(\mathrm{M})$ 


\section{Central Composite Design and Statistical Analysis}

Experiments revealed that the amount of adsorbed dye was very low when $\mathrm{NC}(\mathrm{M})$ was used. The maximum percentage of dye removal was $\approx 31 \%$ at optimum conditions. Indeed, introduction of D-amino glucose monomers decreased hydrophilicity of $\mathrm{NC}(\mathrm{M})$ resulted in repelling the hydrophilic azo dye from the surface of adsorbent [27]. However, percentage of dye removal reached $93.41 \%$ in the presence of $\mathrm{NC}(\mathrm{L})$ with higher hydrophilicity. It can be concluded that hydrophilicity had more effect on the adsorption than the number of functional groups. In This regard, the result of CCD was just reported for NC(L) (Supplementary Information, Table S1).

Least squares method was used for introducing a multiple regression model and estimating the regression coefficients $(\beta)$. A quadratic model was suggested by Design-Expert software according to Eq. (7):

$$
\begin{aligned}
R e \%=83.12 & +1.60 p H+6.59 T+16.06 C_{\mathrm{NC}(\mathrm{L})} \\
& +0.2913 p H \cdot T+2.32 p H \cdot C_{\mathrm{NC}(\mathrm{L})} \\
& -3.44 T \cdot C_{\mathrm{NC}(\mathrm{L})}-0.9868 p H^{2} \\
& -4.26 T^{2}-8.4 C_{\mathrm{NC}(\mathrm{L})}^{2}
\end{aligned}
$$

Fig. 8 confirms that the cumulative normal distribution of residuals is approximately a straight line implying the error $(\varepsilon)$ has a normal distribution [33].

Fig. 8 Normal plot of residuals

Analysis of variance (ANOVA) for quadratic model is presented in Table 4 at $95 \%$ confidence interval.

Table 4 Analysis of variance for quadratic model at $95 \%$ confidence interval

\begin{tabular}{lcccccc}
\hline Source & Sum of Square & DF & Mean Square & $\boldsymbol{F}$-value & $\boldsymbol{p}$-value & \\
\hline Model & 3615.62 & 9 & 401.74 & 45.22 & $<0.0001$ & significant \\
$p H$ & 22.42 & 1 & 22.42 & 2.52 & 0.1508 & \\
$T$ & 592.76 & 1 & 592.76 & 66.72 & $<0.0001$ & \\
$C_{\mathrm{NC}(\mathrm{L})}$ & 2251.83 & 1 & 2251.83 & 253.47 & $<0.0001$ & \\
$p H \cdot T$ & 0.6788 & 1 & 0.6788 & 0.0764 & 0.7892 & \\
$p H \cdot C_{\mathrm{NC}(\mathrm{L})}$ & 42.88 & 1 & 42.88 & 4.83 & 0.0593 & \\
$T \cdot C_{\mathrm{NC}(\mathrm{L})}$ & 94.74 & 1 & 94.74 & 10.66 & 0.0114 & \\
$p H^{2}$ & 7.30 & 1 & 7.30 & 0.8221 & 0.3911 & \\
$T^{2}$ & 241.93 & 1 & 241.93 & 27.23 & 0.0008 & \\
$C_{\mathrm{NC}(\mathrm{L})}{ }^{2}$ & 530.51 & 1 & 530.51 & 59.72 & $<0.0001$ & \\
Residual & 71.07 & 8 & 8.88 & & & \\
$\quad$ Lack of Fit & 44.84 & 3 & 14.95 & 2.85 & 0.1444 & not significant \\
$\quad$ Pure Error & 26.23 & 5 & 5.25 & & & \\
Corrected Total & 3686.69 & 17 & & & & \\
\hline
\end{tabular}


As can be seen, the $p$-value were greater than 0.05 for terms of $p H, p H \cdot T$ and $p H^{2}$ which implied that they were not significant in the model. However, the term of $p H \cdot C_{\mathrm{NC}(\mathrm{L})}$ had little effect on the response. As well, the $p$-value for Lack of fit $(=0.1444)$ showed that the model was adequate to predict the experimental data.

Results of statistic for testing the adequacy of model are summarized in Table 5.

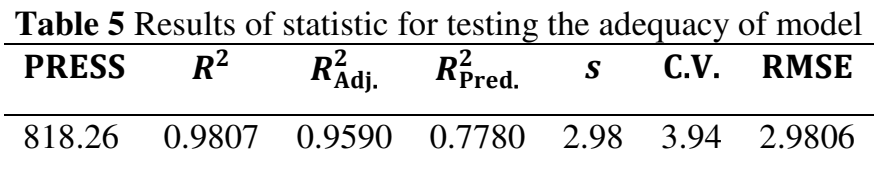

Difference between $R_{\text {Pred. }}^{2}$ and $R_{\text {Adj. was less than }}^{2} 0.2$ which was reasonable. Since adequate precision (ratio of signal to noise) was greater than 4 , the ratio was desirable. In this regard, the predicted values of response were consistent with observed results (Supplementary Information, Table S1). The values of the predicted response versus observed response is plotted in Fig. 9. As can be seen, the points lay along a straight line. This line was obtained by the least squares method.

Fig. 9 Plot of predicted response versus observed response

\section{Influence of Nanocomposite Concentration-Initial pH on the Percentage of Dye Removal}

Central Composite Design gives opportunity to study the influence of variables on the response and obtain mutual interactions [45]. The 3D response surface plot for percentage of dye removal versus nanocomposite concentration and initial $\mathrm{pH}$ is depicted in Fig. 10. High levels of variables had positive influence on the response.

Fig. 10 Response surface plot for percentage of dye removal as a function of nanocomposite concentration and initial $\mathrm{pH}$ at temperature of $43.0{ }^{\circ} \mathrm{C}$

The interaction between $C_{\mathrm{NC}(\mathrm{L})}$ and $\mathrm{pH}$ was studied by plotting interaction graph in Fig. 11 . When the level of nanocomposite dosage was low $\left(0.6 \mathrm{~g} \cdot \mathrm{L}^{-1}\right)$, there was no significant changes in response at any pHs. On the contrary, an increase in concentration $\left(2.0 \mathrm{~g} \cdot \mathrm{L}^{-1}\right)$ led to higher percentage of dye removal in the whole range of $\mathrm{pH}$. Furthermore, the effect of alkaline medium was considerable when $C_{\mathrm{NC}(\mathrm{L})}$ increased. For example, when $\mathrm{pH}$ was 5.50 , the increase in the concentration resulted in a $27.7 \%$ growth in $R e \%$. However, the growth of $R e \%$ was $36.7 \%$ at $\mathrm{pH}$ of 9.50. Point of zero charge $\mathrm{pH}\left(\mathrm{pH}_{\mathrm{pzc}}\right)$ was 3.9 for $\mathrm{NC}(\mathrm{L})[20]$ and the charge of adsorbent 
was negative at $\mathrm{pHs}$ greater than $\mathrm{pH}_{\mathrm{pzc}}$. At high $\mathrm{pHs}$, anions of carboxylate $\left(-\mathrm{COO}^{-}\right)$and hydroxyl $\left(\mathrm{OH}^{-}\right)$were produced on the surface of $\mathrm{NC}(\mathrm{L})$. Thus, there was an electrostatic attraction between active sites of adsorbent and cationic dye molecules [46]. Relevantly, more anions were accessible when the concentration increased [47].

Fig. 11 Percentage of dye removal versus $\mathrm{pH}$ at two different nanocomposite concentrations with $95 \%$ confidence interval and temperature of $43.0{ }^{\circ} \mathrm{C}$

\section{Influence of Nanocomposite Concentration-Temperature on the Percentage of Dye Removal}

Fig. 12 shows the influence of nanocomposite concentration and temperature on the percentage of BB41 removal. By following the variations, it was concluded that the adsorption was endothermic and higher temperature was in favor of adsorption [22]. It implied that the adsorption process was controlled by the dye diffusion into the surface and pores of nanocomposite [48]. Dye removal increased when the concentration of NC(L) increased. The surface of nanocomposite is covered by different functional groups such as carboxyl, hydroxyl, amine and aromatic rings. When more functional groups were available (as a result of increased concentration), more interactions including electrostatic interaction, hydrogen bonding, cation$\pi$ and $\pi-\pi$ stacking between dye and adsorbent were possible. The interaction plot (Fig. 13) confirms that higher efficiency of adsorption needs elevated temperature and concentration. At low level of temperature $\left(28.0{ }^{\circ} \mathrm{C}\right)$, the percentage of dye removal was $44.4 \%$ at concentration of $0.6 \mathrm{~g} \cdot \mathrm{L}^{-1}$ and $R e \%$ reached $83.4 \%$ at $2.0 \mathrm{~g} \cdot \mathrm{L}^{-1}$. However, at $T=58.0{ }^{\circ} \mathrm{C}$, the difference between $R e \%$ was $31.8 \%$ when concentration changed from 0.6 to $2.0 \mathrm{~g} \cdot \mathrm{L}^{-1}$.

Fig. 12 Response surface plot for percentage of dye removal as a function of nanocomposite concentration and temperature at $\mathrm{pH}$ of 7.50

Fig. 13 Percentage of dye removal versus temperature at two different nanocomposite concentrations with 95\% confidence interval and $\mathrm{pH}$ of 7.50

\section{Influence of Initial pH-Temperature on the Percentage of Dye Removal}

The impact of pH-temperature on the dye removal efficiency is illustrated in Fig. 14. The percentage of BB41 removal was not significantly changed by increasing the initial $\mathrm{pH}$. However, rising temperature led to higher adsorption and $R e \%$. For instance, $R e \%$ changed from $72.2 \%$ (at $28.0{ }^{\circ} \mathrm{C}$ ) to $85.4 \%$ (at $58.0{ }^{\circ} \mathrm{C}$ ) by rising temperature. Fig. 15 clearly presents the interaction between $\mathrm{pH}$ and temperature. The adsorption was not affected too much by $\mathrm{pH}$ 
at constant temperature. However, warmer solution led to more dye adsorption at a specific $\mathrm{pH}$ [49]. It could be interpreted that more facile diffusion was possible at higher temperature [48].

Fig. 14 Response surface plot for percentage of dye removal as a function of $\mathrm{pH}$ and temperature at nanocomposite concentration of $1.30 \mathrm{~g} \cdot \mathrm{L}^{-1}$

Fig. 15 Percentage of dye removal versus $\mathrm{pH}$ at two temperatures with $95 \%$ confidence interval and nanocomposite concentration of $1.30 \mathrm{~g} \cdot \mathrm{L}^{-1}$

\section{Optimization and Adsorption Mechanism}

Finding the conditions in which the process is optimized is one the important challenges in the industries. By using analytical and mathematical techniques, numerical optimization was done [45]. In this regard, maximum $R e \%$ was calculated $93.4 \%$ when $\mathrm{pH}$ was 9.02 at temperature of $47.1{ }^{\circ} \mathrm{C}$ and nanocomposite concentration of $1.98 \mathrm{~g} \cdot \mathrm{L}^{-1}$. The experimental result of $R e \%$ was $95.4 \%$ which was consistent with the calculated value $(93.4 \%)$.

Percentage of BB41 removal is reported in Table 6 when CS(L), DTPA-CS(L), GO and $\mathrm{NC}(\mathrm{L})$ were used as the adsorbent at optimum conditions. The data confirmed that there was a synergism effect when different functional groups were attached to the surface of the NC(L) The active groups were carboxyl (originated from GO and DTPA), hydroxyl (originated from APTES, GO and CS(L)), amine (in the CS(L) structure) and aromatic rings (in the GO sheets). Thus, the possible adsorption mechanisms could be electrostatic interactions between functional groups of $\mathrm{NC}(\mathrm{L})$ and cationic dye. When $\mathrm{pH}$ was much greater than $\mathrm{pH}_{\mathrm{pzc}}$, the carboxyl and hydroxyl groups were negative in the surface of adsorbent resulted in the attracting BB41 [50]. Besides, there were cation- $\pi$ interactions as a noncovalent bonding between cationic dye and $\pi$ system, along with $\pi$ - $\pi$ stacking resulted from $\pi$ electrons in the aromatic portions of BB41 and conjugated aromatic rings of GO [18]. H-bonding could serve as other factors in adsorption mechanism [51].

Table 6 Percentage of BB41 removal using ingredients and $\mathrm{NC}(\mathrm{L})$ at optimum conditions

\begin{tabular}{ll}
\hline Adsorbent & $\boldsymbol{R e} \%$ \\
\hline CS(L) & 36.0 \\
DTPA-CS(L) & 52.0 \\
GO & 81.4 \\
NC(L) & 95.4 \\
\hline
\end{tabular}

\section{Kinetics Adsorption Studies}

In order to design an adsorption reactor, it is crucial to obtain the constant of adsorption 
rate. In this regard, the uptake rate of dye is studied at optimum conditions ( $\mathrm{pH}$ of 9.02, temperature of $47.1{ }^{\circ} \mathrm{C}$ and $\mathrm{NC}(\mathrm{L})$ concentration of $\left.1.98 \mathrm{~g} \cdot \mathrm{L}^{-1}\right)$. The results of kinetics studies are presented in Fig. 16, Fig. 17 and Fig. 18 for concentration of $8.0 \mathrm{mg} \cdot \mathrm{L}^{-1}, 15.0 \mathrm{mg} \cdot \mathrm{L}^{-1}$ and $30.0 \mathrm{mg} \cdot \mathrm{L}^{-1}$, respectively.

Fig. 16 Experimental and fitted kinetics data for adsorption of BB41 with concentration of $8.0 \mathrm{mg} \cdot \mathrm{L}^{-1}$ under optimum conditions

Fig. 17 Experimental and fitted kinetics data for adsorption of BB41 with concentration of $15.0 \mathrm{mg} \cdot \mathrm{L}^{-1} \mathrm{under}$ optimum conditions

Fig. 18 Experimental and fitted kinetics data for adsorption of BB41 with concentration of $30.0 \mathrm{mg} \cdot \mathrm{L}^{-1} \mathrm{under}$ optimum conditions

For all concentrations, the dye adsorption was quite fast. For example, about $65.93 \%$ of dye with the initial concentration of $8.0 \mathrm{mg} \cdot \mathrm{L}^{-1}$ was removed within the first $20 \mathrm{~min}$. The percentage of BB41 removal was 61.49 and $47.15 \%$ after 20 min when the initial concentrations were 15.0 and $30.0 \mathrm{mg} \cdot \mathrm{L}^{-1}$, respectively. The dye removal was followed by a mild-slope adsorption and equilibrium was achieved at $30 \mathrm{~min}$. Some kinetics models were listed in Table 7 and used for fitting the experimental data.

Table 7 Different kinetics models used for fitting the experimental data

\begin{tabular}{lcc}
\hline \multicolumn{1}{c}{ Kinetics model } & Two parameters models & Reference \\
\hline & $q_{\mathrm{t}}=q_{\mathrm{e}}\left(1-\exp \left(-k_{1} t\right)\right)$ & {$[52]$} \\
$\begin{array}{l}\text { Pseudo-first-order (PFO) } \\
\text { Pseudo-second-order (PSO) }\end{array}$ & $q_{\mathrm{t}}=q_{\mathrm{e}}^{2} k_{2} t /\left(1+q_{\mathrm{e}} k_{2} t\right)$ & {$[53]$} \\
Elovich & $q_{\mathrm{t}}=\left(1 / b_{\mathrm{E}}\right) \ln \left(1+a_{\mathrm{E}} b_{\mathrm{E}} t\right)$ & {$[54]$} \\
& Three parameters models & {$[55]$} \\
$\begin{array}{l}\text { Mixed 1, 2-order (MOE) } \\
\text { Pseudo-n-order (PnO) }\end{array}$ & $q_{\mathrm{t}}=q_{\mathrm{e}}\left(1-\exp \left(-k_{1} t\right)\right) /\left(1-F_{2} \exp \left(-k_{1} t\right)\right)$ & {$[56]$} \\
Modified pseudo-n-order (MPnO) & $q_{\mathrm{t}}=q_{\mathrm{e}}-\left((n-1) k_{1} t+q_{\mathrm{e}}^{1-n}\right)^{\frac{1}{1-n}}$ & [57] \\
$\begin{array}{l}\text { Fractal-like pseudo-first-order } \\
\text { (FL-PSO) }\end{array}$ & $q_{\mathrm{t}}=q_{\mathrm{e}}\left(1-\exp \left(-n k^{\prime} t\right)\right)^{\frac{1}{n}}$ & [58] \\
$\begin{array}{l}\text { Fractal-like pseudo-second-order } \\
\text { (FL-PSO) }\end{array}$ & $q_{\mathrm{t}}=q_{\mathrm{e}}\left(1-\exp \left(-k_{1}^{\prime} t^{\alpha}\right)\right)$ & [59] \\
\hline
\end{tabular}

The adequacy of the models was checked by $R_{\text {Adj. }}^{2}$, corrected Akaike information criterion $\left(\mathrm{AIC}_{\mathrm{c}},\right)$, chi-square $\left(\chi^{2}\right)$ and $\mathrm{RMSE}$. The $\mathrm{AIC}_{\mathrm{c}}$ and $\chi^{2}$ were calculated by the following equations, respectively $[60,61]$ :

$$
\mathrm{AIC}_{\mathrm{c}}=1+\ln \left(\frac{\mathrm{SS}_{\text {residual }}}{n}\right)+\frac{2(p+1)}{n-p-2}
$$




$$
\chi^{2}=\sum_{\mathrm{i}=1}^{n} \frac{\left(q_{\mathrm{exp}, \mathrm{i}}-q_{\mathrm{cal}, \mathrm{i}}\right)^{2}}{q_{\mathrm{cal}, \mathrm{i}}}
$$

in which, $n$ was the number of experimental data and $p$ was the parameters number.

The parameters and goodness of fit for each model were obtained by non-linear regression. The results are presented in Table 8 .

Table 8 Model parameters along with $\boldsymbol{R}_{\text {Adj. }}^{2}$ AIC,$\chi^{2}$ and RMSE obtained by non-linear regression

\begin{tabular}{|c|c|c|c|c|c|c|c|c|}
\hline Model & $C_{0}\left(\mathrm{mg} \cdot \mathrm{L}^{-1}\right)$ & \multicolumn{3}{|c|}{ Parameter } & \multicolumn{4}{|c|}{ Goodness of Fit } \\
\hline \multirow[t]{4}{*}{ PFO } & & $q_{\mathrm{e}}\left(\mathbf{m g} \cdot \mathrm{g}^{-1}\right)$ & $k_{1}$ & - & $R_{\text {Adj. }}^{2}$ & $\mathrm{AIC}_{\mathrm{c}}$ & $\chi^{2}$ & RMSE \\
\hline & 8.0 & 2.77 & 0.101 & & 0.9901 & -2.7915 & 0.0688 & 0.1082 \\
\hline & 15.0 & 6.16 & 0.073 & & 0.9927 & -1.5455 & 0.2834 & 0.2017 \\
\hline & 30.0 & 9.27 & 0.131 & & 0.9743 & 0.4419 & 1.0059 & 0.5448 \\
\hline \multirow[t]{4}{*}{ PSO } & & $q_{\mathrm{e}}\left(\mathrm{mg} \cdot \mathrm{g}^{-1}\right)$ & $\boldsymbol{k}_{2}$ & - & $R_{\mathrm{Adj}}^{2}$ & $\mathrm{AIC}_{\mathrm{c}}$ & $\chi^{2}$ & RMSE \\
\hline & 8.0 & 3.24 & 0.035 & & 0.9898 & -2.7631 & 0.0952 & 0.1097 \\
\hline & 15.0 & 7.40 & 0.011 & & 0.9954 & -2.0073 & 0.1394 & 0.1601 \\
\hline & 30.0 & 10.50 & 0.015 & & 0.9944 & -1.0834 & 0.2491 & 0.2541 \\
\hline \multirow[t]{4}{*}{ Elovich } & & $a_{\mathrm{E}}$ & $b_{\mathrm{E}}$ & - & $R_{\text {Adj. }}^{2}$ & $\mathrm{AIC}_{\mathrm{c}}$ & $\chi^{2}$ & RMSE \\
\hline & 8.0 & 0.592 & 1.36 & & 0.9653 & -1.5407 & 0.2766 & 0.2022 \\
\hline & 15.0 & 0.842 & 0.548 & & 0.9824 & -0.6610 & 0.2697 & 0.3139 \\
\hline & 30.0 & 3.524 & 0.478 & & 0.9872 & -0.2588 & 0.1681 & 0.3838 \\
\hline \multirow[t]{4}{*}{ MOE } & & $q_{\mathrm{e}}\left(\mathrm{mg} \cdot \mathrm{g}^{-1}\right)$ & $k_{1}$ & $F_{2}$ & $R_{\mathrm{Adj}}^{2}$ & $\mathrm{AIC}_{\mathrm{c}}$ & $\chi^{2}$ & RMSE \\
\hline & 8.0 & 2.85 & 0.058 & 0.49 & 0.9918 & -2.6193 & 0.0666 & 0.0986 \\
\hline & 15.0 & 11.47 & 0.040 & 1.78 & 0.9962 & -1.8237 & 0.1459 & 0.1467 \\
\hline & 30.0 & 10.50 & 0.000 & 1.00 & 0.9937 & -0.6072 & 0.2491 & 0.2541 \\
\hline \multirow[t]{4}{*}{ PnO } & & $q_{\mathrm{e}}\left(\mathrm{mg} \cdot \mathrm{g}^{-1}\right)$ & $k_{1}$ & $n$ & $R_{\text {Adj. }}^{2}$ & $\mathrm{AIC}_{\mathrm{c}}$ & $\chi^{2}$ & RMSE \\
\hline & 8.0 & 2.89 & 0.076 & 1.34 & 0.9919 & -2.6352 & 0.0629 & 0.0978 \\
\hline & 15.0 & 6.70 & 0.029 & 1.51 & 0.9958 & -1.7440 & 0.1528 & 0.1527 \\
\hline & 30.0 & 11.87 & 0.002 & 2.78 & 0.9951 & -0.8557 & 0.1395 & 0.2380 \\
\hline \multirow[t]{4}{*}{ MPnO } & & $q_{\mathrm{e}}\left(\mathrm{mg} \cdot \mathrm{g}^{-1}\right)$ & $\boldsymbol{k}^{\prime}$ & $n$ & $R_{\text {Adj. }}^{2}$ & $\mathrm{AIC}_{\mathbf{c}}$ & $\chi^{2}$ & RMSE \\
\hline & 8.0 & 2.80 & 0.083 & 1.10 & 0.9928 & -2.7438 & 0.0629 & 0.0926 \\
\hline & 15.0 & 6.28 & 0.045 & 1.23 & 0.9982 & -2.5805 & 0.0771 & 0.1005 \\
\hline & 30.0 & 9.81 & 0.030 & 1.83 & 0.9994 & -3.0175 & 0.0112 & 0.0808 \\
\hline \multirow[t]{4}{*}{ FL-PFO } & & $q_{\mathrm{e}}\left(\mathrm{mg} \cdot \mathrm{g}^{-1}\right)$ & $k_{1}^{\prime}$ & $a$ & $R_{\mathrm{Adj}}^{2}$ & $\mathrm{AIC}_{\mathrm{c}}$ & $\chi^{2}$ & RMSE \\
\hline & 8.0 & 2.82 & 0.119 & 0.90 & 0.9907 & -2.4958 & 0.0778 & 0.1048 \\
\hline & 15.0 & 6.31 & 0.093 & 0.87 & 0.9981 & -2.5451 & 0.0889 & 0.1023 \\
\hline & 30.0 & 10.00 & 0.209 & 0.67 & 0.9990 & -2.4440 & 0.0202 & 0.1076 \\
\hline \multirow[t]{4}{*}{ FL-PSO } & & $q_{\mathrm{e}}\left(\mathrm{mg} \cdot \mathrm{g}^{-1}\right)$ & $\boldsymbol{k}_{2}^{\prime}$ & $a$ & $R_{\text {Adj. }}^{2}$ & $\mathrm{AIC}_{\mathbf{c}}$ & $\chi^{2}$ & RMSE \\
\hline & 8.0 & 3.00 & 0.029 & 1.23 & 0.9926 & -2.7248 & 0.0466 & 0.0935 \\
\hline & 15.0 & 7.14 & 0.010 & 1.07 & 0.9953 & -1.6285 & 0.1813 & 0.1618 \\
\hline & 30.0 & 11.31 & 0.016 & 0.83 & 0.9968 & -1.2797 & 0.0641 & 0.1926 \\
\hline
\end{tabular}

The best model to describe the adsorption rate of BB41 was MPnO kinetics model which had $R_{\mathrm{Adj} .}^{2}$ close to unity, lesser $\mathrm{AIC}_{\mathrm{c}}, \chi^{2}$ and RMSE.

Many steps are involved in the adsorption process such as external mass transfer of dye from the bulk of solution, film diffusion and internal diffusion of dye into the composite sites, and eventually the adsorption itself [62]. Weber and Morris showed [63] that if the intra-particle 
diffusion stage was the main rate-limiting step, the plot of $q_{\mathrm{t}}$ versus $t^{0.5}$ could be linear passing through the origin according to Eq. (10):

$$
q_{\mathrm{t}}=K_{\mathrm{dif}} t^{0.5}+C
$$

where, $K_{\text {dif }}$ was to the intra-particle diffusion rate constant and $C$ was the intercept.

However, a multi-linear plot indicates that the adsorption process is divided into different steps [64]. The profile presented in Fig. 19 has two linear segments. This kind of variation implied that there was an immediate and external surface adsorption at stage (I) followed by a gradual sorption at stage (II). Indeed, the process was controlled by film diffusion at stage (I) and the line with the lower slope (stage (II)) was attributed to the lower adsorption rate and intra-particle diffusion was the rate limiting step $[65,66]$.

Fig. 19 Intra-particle diffusion plot for BB41 adsorption at different concentrations under optimum conditions

\section{Equilibrium Adsorption Results}

The distribution of BB41 between solution and $\mathrm{NC}(\mathrm{L})$ can be demonstrated by isotherms at equilibrium. The experimental results were fitted by different isotherms. The most common adsorption isotherms are listed in Table 9.

Table 9 Different isotherms used for fitting the experimental data

\begin{tabular}{llc}
\hline \multicolumn{1}{c}{ Isotherm } & \multicolumn{1}{c}{ Two parameters models } & Reference \\
\hline \multirow{2}{*}{$\begin{array}{l}\text { Langmuir } \\
\text { Treundlich }\end{array}$} & $q_{\mathrm{e}}=q_{\mathrm{m}} K_{\mathrm{L}} C_{\mathrm{e}} /\left(1+K_{\mathrm{L}} C_{\mathrm{e}}\right)$ & {$[67]$} \\
Temkin & $q_{\mathrm{e}}=K_{\mathrm{F}} C_{\mathrm{e}}^{\mathrm{c}}$ & {$[68]$} \\
Modified Langmuir & $q_{\mathrm{e}}=\left(R T / b_{\mathrm{T}}\right) \ln \left(K_{\mathrm{T}} C_{\mathrm{e}}\right)$ & {$[69]$} \\
& $q_{\mathrm{e}}=q_{\mathrm{m}} K_{\mathrm{ML}} C_{\mathrm{e}} /\left(\left(C_{\mathrm{s}}-C_{\mathrm{e}}\right)+K_{\mathrm{ML}} C_{\mathrm{e}}\right)$ & {$[70]$} \\
Redlich-Peterson & $\quad$ Three parameters models & {$[71]$} \\
Toth & $q_{\mathrm{e}}=K_{\mathrm{RP}} C_{\mathrm{e}} /\left(1+\alpha_{\mathrm{RP}} C_{\mathrm{e}}^{\beta}\right)$ & {$[72]$} \\
Extended Langmuir & $q_{\mathrm{e}}=q_{\mathrm{m}} a_{\mathrm{T}} C_{\mathrm{e}} /\left(1+\left(a_{\mathrm{T}} C_{\mathrm{e}}\right)^{\mathrm{c}}\right)^{1 / \mathrm{c}}$ & {$[73]$} \\
Langmuir-Freundlich & $q_{\mathrm{e}}=q_{\mathrm{m}} K_{\mathrm{EL}} C_{\mathrm{e}} /\left(1+K_{\mathrm{EL}} C_{\mathrm{e}}+\left(a\left(K_{\mathrm{EL}} C_{\mathrm{e}}\right)^{1 / 2}\right)\right)$ & {$[74]$} \\
Modified Langmuir-Freundlich & $q_{\mathrm{e}}=\left(q_{\mathrm{m}}\left(K_{\mathrm{LF}} C_{\mathrm{e}}\right)^{\mathrm{c}}\right) /\left(1+\left(K_{\mathrm{LF}} C_{\mathrm{e}}\right)^{\mathrm{c}}\right)$ & {$[70]$} \\
\hline
\end{tabular}

The adsorption isotherms for BB41 on $\mathrm{NC}(\mathrm{L})$ are depicted in Fig. 20. An increase in adsorption capacity was observed as the equilibrium concentration of dye increased until NC(L) was saturated.

Fig. 20 Adsorption isotherms for adsorption of BB41 under optimum conditions 
The parameters and goodness of fit are presented in Table 10.

Table 10 Isotherm parameters along with $\boldsymbol{R}_{\text {Adj. }}^{2}$ AIC,$\chi^{2}$ and RMSE obtained by non-linear regression

\begin{tabular}{|c|c|c|c|c|c|c|c|}
\hline \multirow{2}{*}{$\begin{array}{l}\text { Isotherm } \\
\text { Langmuir }\end{array}$} & \multicolumn{3}{|c|}{ Parameter } & \multicolumn{4}{|c|}{ Goodness of Fit } \\
\hline & $q_{\mathrm{m}}\left(\mathbf{m g} \cdot \mathbf{g}^{-1}\right)$ & $K_{\mathrm{L}}$ & - & $R_{\mathrm{Adj}}^{2}$ & $\mathrm{AIC}_{\mathrm{c}}$ & $\chi^{2}$ & RMSE \\
\hline & 46.48 & -1261773 & & 0.6712 & 6.3854 & 17.2714 & 1.1070 \\
\hline \multirow[t]{2}{*}{ Freundlich } & $K_{F}$ & $c$ & - & $R_{\text {Adj. }}^{2}$ & $\mathrm{AIC}_{\mathrm{c}}$ & $\chi^{2}$ & RMSE \\
\hline & 19.15 & 0.17 & & 0.9702 & 3.8496 & 1.5797 & 2.8190 \\
\hline \multirow[t]{2}{*}{ Temkin } & $b_{\mathrm{T}}$ & $\boldsymbol{K}_{\mathrm{T}}$ & - & $R_{\text {Adj. }}^{2}$ & $\mathrm{AIC}_{\mathrm{c}}$ & $\chi^{2}$ & RMSE \\
\hline & 351.17 & 2.72 & & 0.9897 & 3.0393 & 0.6220 & 2.0098 \\
\hline \multirow{2}{*}{$\begin{array}{l}\text { Modified } \\
\text { Langmuir }\end{array}$} & $q_{\mathrm{m}}\left(\mathrm{mg} \cdot \mathrm{g}^{-1}\right)$ & $K_{\mathrm{ML}}$ & - & $R_{\text {Adj. }}^{2}$ & $\mathrm{AIC}_{\mathrm{c}}$ & $\chi^{2}$ & RMSE \\
\hline & 46.48 & -890953 & & 0.6712 & 6.3856 & 17.2743 & 10.0180 \\
\hline \multirow{2}{*}{$\begin{array}{l}\text { Redlich- } \\
\text { Peterson }\end{array}$} & $K_{\mathrm{RP}}$ & $a_{\mathrm{RP}}$ & $\boldsymbol{\beta}$ & $R_{\text {Adj. }}^{2}$ & $\mathrm{AIC}_{\mathrm{c}}$ & $\chi^{2}$ & RMSE \\
\hline & 11390440 & 594921 & 0.83 & 0.9702 & 4.4496 & 1.5797 & 2.8119 \\
\hline \multirow[t]{2}{*}{ Toth } & $q_{\mathrm{m}}\left(\mathrm{mg} \cdot \mathrm{g}^{-1}\right)$ & $a_{\mathrm{T}}$ & $c$ & $R_{\text {Adj. }}^{2}$ & $\mathrm{AIC}_{\mathrm{c}}$ & $\chi^{2}$ & RMSE \\
\hline & 63.53 & 0.18 & 0.54 & 0.9954 & 2.5808 & 0.2265 & 1.1838 \\
\hline \multirow{2}{*}{$\begin{array}{l}\text { Extended } \\
\text { Langmuir }\end{array}$} & $q_{\mathrm{m}}\left(\mathrm{mg} \cdot \mathrm{g}^{-1}\right)$ & $K_{\mathrm{EL}}$ & $a$ & $R_{\text {Adj. }}^{2}$ & $\mathrm{AIC}_{\mathrm{c}}$ & $\chi^{2}$ & RMSE \\
\hline & 64.63 & 0.18 & 1.66 & 0.9953 & 2.5981 & 0.2270 & 1.1941 \\
\hline \multirow{2}{*}{$\begin{array}{l}\text { Langmuir- } \\
\text { Freundlich }\end{array}$} & $q_{\mathrm{m}}\left(\mathrm{mg} \cdot \mathrm{g}^{-1}\right)$ & $K_{\mathrm{LF}}$ & $c$ & $R_{\text {Adj. }}^{2}$ & $\mathrm{AIC}_{\mathrm{c}}$ & $\chi^{2}$ & RMSE \\
\hline & 61.88 & 0.045 & 0.64 & 0.9958 & 2.4956 & 0.2063 & 1.1345 \\
\hline \multirow{2}{*}{$\begin{array}{l}\text { Modified } \\
\text { Langmuir- } \\
\text { Freundlich }\end{array}$} & $q_{\mathrm{m}}\left(\mathrm{mg} \cdot \mathrm{g}^{-1}\right)$ & $K_{\mathrm{MLF}}$ & $c$ & $R_{\text {Adj. }}^{2}$ & $\mathrm{AIC}_{\mathrm{c}}$ & $\chi^{2}$ & RMSE \\
\hline & 55.87 & 41.77 & 0.70 & 0.9972 & 2.0713 & 0.1469 & 0.9176 \\
\hline
\end{tabular}

Among models, the modified Langmuir-Freundlich isotherm was the best one to fit the experimental data. This equation takes into account the heterogeneity of the adsorbent surface which is in agreement with the structure of $\mathrm{NC}(\mathrm{L})$ [70]. The maximum capacity of adsorbent was calculated $55.87 \mathrm{mg} \cdot \mathrm{g}^{-1}$ which was comparable with other investigations [75, 76]. Table 11 represents the amount of $q_{\mathrm{m}}$ obtained by different adsorbents for BB41 removal.

Table 11 Comparing the maximum adsorption capacity of adsorbent used for BB41 removal

\begin{tabular}{lccc}
\hline Adsorbent & $\begin{array}{c}\boldsymbol{T} \\
(\mathbf{C})\end{array}$ & $\begin{array}{c}\boldsymbol{q}_{\mathbf{m}} \\
\left(\mathbf{m g} \cdot \mathbf{g}^{-\mathbf{1}}\right)\end{array}$ & Reference \\
\hline Biochar derived from bio-wastes of rice husk & 35 & 17.60 & {$[75]$} \\
Saccharomyces cerevisiae & 20 & 23.5 & {$[76]$} \\
Dispersed carbon particles & 25 & 41.40 & {$[35]$} \\
Pistachio shell & 50 & 41.77 & {$[49]$} \\
Titanium (IV) oxide/calcium alginate & 20 & 141.92 & {$[77]$} \\
Zeolite tuff & 50 & 192.31 & {$[78]$} \\
NC(L) & 47.1 & 55.87 & Present work \\
\hline
\end{tabular}

The synthesized $\mathrm{NC}(\mathrm{L})$ had reasonable maximum adsorption capacity and was able to adsorb dye in $30 \mathrm{~min}$. Also, adsorbent with magnetic property was separated from treated solution within a few seconds.

\section{Cyclic Regeneration of Adsorbent}

Not only are the value of maximum dye uptake and the rate of adsorption important but also, adsorbent recovery is crucial for scale-up purposes. The experiments showed that the 
acidic medium associated with ultrasonic waves caused to achieve a desirable desorption. Actually, the adsorbent was protonated in acid solution and BB41 was desorbed from the surface of $\mathrm{NC}(\mathrm{L})$ [36]. A facile desorption was obtained using ultrasonic waves since waves weakened the interaction between adsorbent and BB41. Fig. 21 shows the percentage of dye removal $(R e \%)$ after recovery cycles. The desorption-adsorption cycle was repeated seven times and the efficiency of $\mathrm{NC}(\mathrm{L})$ decreased only $12 \%$.

Fig. 21 Percentage of dye removal after recovery

\section{Conclusions}

In this study, the effect of molecular weight of chitosan on the efficiency of nano-magnetic inorganic-organic adsorbents was studied. The silica-modified magnetite nanoparticles were treated with medium-molecular weight chitosan, graphene oxide and diethylenetriaminepentaacetic acid. Techniques including FT-IR, XRD, FESEM, TGA/DTG, VSM and nitrogen adsorption/desorption isotherm were applied for characterization of adsorbent $(\mathrm{NC}(\mathrm{M})$ ). The adsorption behavior of synthesized nanocomposite was compared with as-prepared adsorbent containing low-molecular weight chitosan ( $\mathrm{NC}(\mathrm{L}))$. $\mathrm{NC}(\mathrm{L})$ ) was a better adsorbent due to having more hydrophilic property and the basic blue 41 was successfully removed from aqueous solutions. Central Composite Design based on the response surface methodology was used for investigating the effective parameters on the adsorption and obtaining the optimum conditions. The maximum dye removal was achieved at $\mathrm{pH}$ of 9.02, temperature of $47.1{ }^{\circ} \mathrm{C}$ and $\mathrm{NC}(\mathrm{L})$ concentration of $1.98 \mathrm{~g} \cdot \mathrm{L}^{-1} \cdot \mathrm{H}$-bonding, coulumbic attraction and pi-stacking interactions were the major factors of adsorption. The dye adsorption was completed within $30 \mathrm{~min}$ at optimum conditions. The film and intra-particle diffusions were rate-limiting steps sequentially. The modified pseudo-n-order equation was the best kinetics model to recreate the kinetics data. The equilibrium experimental data were fitted by modified Langmuir-Freundlich isotherm and the maximum adsorption capacity was $55.87 \mathrm{mg} \cdot \mathrm{g}^{-1}$. Due to the physiosorption of dye, the acidic medium associated with ultrasound caused the adsorbent to recover even after seven cycles.

\section{Acknowledgments}

The authors would like to thank Bu-Ali Sina University for supporting this work.

\section{Declarations}


Funding The research leading to these results received funding from Bu-Ali Sina University.

Conflicts of interest The authors declare that there is no conflict of interest.

Availability of data and material All data and materials as well as software application support published claims and comply with field standards.

Authors' contributions Simin Asadabadi: Conceptualization, Methodology, Funding acquisition, Project administration, Writing-original draft, Writing-review \& editing. Masouma Mirzai: Investigation, Validation, Writing-original draft.

Ethics approval It is declared that this manuscript is containing original research, and has not been published in any journal, and is not being simultaneously considered for publication elsewhere. Submission of this paper has been made with full responsibility, based on the journal requirements, and there are no plagiarism and concerns about animal or human experimentation. The manuscript has been approved by authors who have significantly contributed and agreed with its submission to Journal of Polymers and the Environment.

Electronic supplementary information Electronic supplementary information associated with this article can be found in the online version. All data generated or analyzed during this study are included in supplementary information files.

\section{References}

1. Punia P, Bharti MK, Chalia S, Dhar R, Ravelo B, Thakur P, Thakur A (2021) Recent advances in synthesis, characterization, and applications of nanoparticles for contaminated water treatment- A review. Ceram Int 47:1526-1550. https://doi.org/10.1016/j.ceramint.2020.09.050

2. Leonel AG, Mansur AAP, Mansur HS (2021) Advanced functional nanostructures based on magnetic iron oxide nanomaterials for water remediation: A review. Water Res 190:116693-116719. https://doi.org/10.1016/j.watres.2020.116693

3. Rauf MA, Meetani MA, Hisaindee S (2011) An overview on the photocatalytic degradation of azo dyes in the presence of $\mathrm{TiO} 2$ doped with selective transition metals. Desalination 276:13-27. https://doi.org/10.1016/j.desal.2011.03.071

4. Abou Taleb MF, Abou El Fadl FI, Albalwi H (2021) Adsorption of toxic dye in wastewater onto magnetic NVP/CS nanocomposite hydrogels synthesized using gamma radiation. Sep Purif Technol 266:118551118560. https://doi.org/10.1016/j.seppur.2021.118551

5. Khalid A, Arshad M, Crowley D (2010) Biodegradation of Azo Dyes. Springer Berlin Heidelberg

6. Patel H, Vashi RT (2015) Characterization and Treatment of Textile Wastewater. Elsevier Science, Waltham

7. Hasan M, Reza G, Massoumi B, Baghban A, Saraei M (2018) Ionically crosslinked magnetic chitosan/אcarrageenan bioadsorbents for removal of anionic eriochrome black-T. Int J Biol Macromol 113:361-375. https://doi.org/10.1016/j.ijbiomac.2018.02.102

8. Panda SK, Aggarwal I, Kumar H, Prasad L, Kumar A, Sharma A, Vo D-VN, Van Thuan D, Mishra V (2021) Magnetite nanoparticles as sorbents for dye removal: A review. Environ Chem Lett 19:2487-2525. https://doi.org/10.1007/s10311-020-01173-9

9. Kadhom M, Albayati N, Alalwan H, Al-furaiji M (2020) Removal of dyes by agricultural waste. Sustain Chem Pharm 16:100259-100267. https://doi.org/10.1016/j.scp.2020.100259

10. Ramesh P, Padmanabhan V, Saravanan P, Thillainayagam BP (2021) Batch studies of turquoise blue dye (TB) adsorption onto activated carbon prepared from low-cost adsorbents: an ANN approach. Biomass Convers Biorefin. https://doi.org/10.1007/s13399-021-01355-7

11. Jazzar A, Alamri H, Malajati Y, Mahfouz R, Bouhrara M, Fihri A (2021) Recent advances in the synthesis 
and applications of magnetic polymer nanocomposites. $\mathrm{J}$ Ind Eng Chem 99:1-18. https://doi.org/10.1016/j.jiec.2021.04.011

12. Tamer Y, Özeren MD, Berber H (2021) High adsorption performance of graphene oxide doped double network hydrogels for removal of azo dyes from water and their kinetics. J Polym Environ. https://doi.org/10.1007/s10924-021-02162-x

13. Bello K, Sarojini BK, Narayana B (2019) Design and fabrication of environmentally benign cellulose based hydrogel matrix for selective adsorption of toxic dyes from industrial effluvia. J Polym Res 26:6274. https://doi.org/10.1007/s10965-019-1724-6

14. Saheed IO, Oh W Da, Suah FBM (2021) Chitosan modifications for adsorption of pollutants - A review. J Hazard Mater 408:124889-124904. https://doi.org/10.1016/j.jhazmat.2020.124889

15. Rastgordani M, Zolgharnein J (2021) Simultaneous determination and optimization of titan yellow and reactive blue 4 dyes removal using chitosan@hydroxyapatite nanocomposites. J Polym Environ 29:17891807. https://doi.org/10.1007/s10924-020-01982-7

16. Vakili M, Qiu W, Cagnetta G, Huang J, Yu G (2021) Solvent-free mechanochemical mild oxidation method to enhance adsorption properties of chitosan. Front Environ Sci Eng 15:128-141. https://doi.org/10.1007/s11783-021-1416-4

17. Chen A, Chen S (2009) Biosorption of azo dyes from aqueous solution by glutaraldehyde-crosslinked chitosans. J Hazard Mater 172:1111-1121. https://doi.org/10.1016/j.jhazmat.2009.07.104

18. Jiang X, Pan W, Xiong Z, Zhang Y, Zhao L (2021) Facile synthesis of layer-by-layer decorated graphene oxide based magnetic nanocomposites for $\beta$-agonists/dyes adsorption removal and bacterial inactivation in wastewater. J Alloys Compd 870:159414. https://doi.org/10.1016/j.jallcom.2021.159414

19. Huang L, Li D, Zhang D, Peng H, Ren Y (2020) Facile preparation of taurine modified magnetic chitosan nanocomposites as biodegradable sdsorbents toward methylene blue. Environ Technol 1-14. https://doi.org/10.1080/09593330.2020.1725140

20. Asadabadi S, Merati Z (2021) A tailored magnetic composite synthesized by graphene oxide, chitosan and aminopolycarboxylic acid for diminishing dye contaminant. Cellulose 28:2327-2351. https://doi.org/10.1007/s10570-020-03623-7

21. Usman M, Ahmed A, Yu B, Wang S, Shen Y, Cong H (2021) Simultaneous adsorption of heavy metals and organic dyes by $\beta$-cyclodextrin-chitosan based cross-linked adsorbent. Carbohydr Polym 255:117486. https://doi.org/10.1016/j.carbpol.2020.117486

22. Chen B, Zhao H, Chen S, Long F, Huang B, Yang B, Pan X (2019) A magnetically recyclable chitosan composite adsorbent functionalized with EDTA for simultaneous capture of anionic dye and heavy metals in complex wastewater. Chem Eng J 356:69-80. https://doi.org/10.1016/j.cej.2018.08.222

23. Jin Z, Wang X, Sun Y, Ai Y, Wang X (2015) Adsorption of 4-n-nonylphenol and bisphenol-A on magnetic reduced graphene oxides: A combined experimental and theoretical studies. Environ Sci Technol 49:91689175. https://doi.org/10.1021/acs.est.5b02022

24. Mittal H, Al A, Morajkar PP, Alhassan SM (2021) GO crosslinked hydrogel nanocomposites of chitosan/carboxymethyl cellulose - A versatile adsorbent for the treatment of dyes contaminated wastewater. Int J Biol Macromol 167:1248-1261. https://doi.org/10.1016/j.ijbiomac.2020.11.079

25. Patil RM, Shete PB, Thorat ND, Otari S V, Barick KC, Prasad A, Ningthoujam RS, Tiwale BM, Pawar SH (2014) Superparamagnetic iron oxide/chitosan core/shells for hyperthermia application: Improved colloidal stability and biocompatibility. J Magn Magn Mater 355:22-30. https://doi.org/10.1016/j.jmmm.2013.11.033

26. Huang $\mathrm{X}$, Zhan $\mathrm{X}$, Wen $\mathrm{C}$, Xu F, Luo L (2018) Amino-functionalized magnetic bacterial cellulose/activated carbon composite for $\mathrm{Pb}^{2+}$ and methyl orange sorption from aqueous solution. $\mathrm{J}$ Mater Sci Technol 34:855-863. https://doi.org/10.1016/j.jmst.2017.03.013

27. Liu Y, Zheng H, Han Y, Wu Y, Wang Y, Liu Y, Feng L (2021) Amphiphilic magnetic copolymer for enhanced removal of anionic dyes: Fabrication, application and adsorption mechanism. Colloids Surf A 623:126674-126688. https://doi.org/10.1016/j.colsurfa.2021.126674

28. Kaemkit C, Monvisade P, Siriphannon P, Nukeaw J (2013) Water-soluble chitosan intercalated montmorillonite nanocomposites for removal of basic blue 66 and basic yellow 1 from aqueous solution. J Appl Polym Sci 128:879-887. https://doi.org/10.1002/app.38255

29. Qu S, Yang H, Ren D, Kan S, Zou G, Li D, Li M (1999) Magnetite nanoparticles prepared by precipitation from partially reduced ferric chloride aqueous solutions. J Colloid Interface Sci 215:190-192. https://doi.org/10.1006/jcis.1999.6185

30. Zhou L, Pan S, Chen X, Zhao Y, Zou B, Jin M (2014) Kinetics and thermodynamics studies of pentachlorophenol adsorption on covalently functionalized $\mathrm{Fe}_{3} \mathrm{O}_{4} @ \mathrm{SiO}_{2}-\mathrm{MWCNTs}$ core-shell magnetic microspheres. Chem Eng J 257:10-19. https://doi.org/10.1016/j.cej.2014.07.060

31. Zolfigol MA, Ayazi-Nasrabadi R, Baghery S, Khakyzadeh V, Azizian S (2016) Applications of a novel nano magnetic catalyst in the synthesis of 1,8-dioxo-octahydroxanthene and dihydropyrano[2,3-c]pyrazole 
derivatives. J Mol Catal A Chem 418:54-67. https://doi.org/10.1016/j.molcata.2016.03.027

32. Marcano DC, Kosynkin D V, Berlin JM, Sinitskii A, Sun Z, Slesarev A, Alemany LB, Lu W, Tour JM (2010) Improved synthesis of graphene oxide. ACS Nano 4:4806-4814. https://doi.org/10.1021/nn1006368

33. Montgomery DC, Peck EA, Vining GG (2013) Introduction to Linear Regression Analysis. Wiley, New Jersey

34. Bakhtiari N, Azizian S (2018) Nanoporous carbon derived from MOF-5: A superadsorbent for copper ions. ACS Omega 3:16954-16959. https://doi.org/10.1021/acsomega.8b02278

35. Seifikar F, Azizian S (2019) A facile method for precipitating of dispersed carbon particles prepared by microwave heating and its application for dye removal. $J$ Mol Liq 275:394-401. https://doi.org/10.1016/j.molliq.2018.11.086

36. Zhang H, Dang Q, Liu C, Yu D, Wang Y, Pu X, Liu Y, Liang Y, Cha D (2019) Fabrication of methyl acrylate and tetraethylenepentamine grafted magnetic chitosan microparticles for capture of Cd(II) from aqueous solutions. J Hazard Mater 366:346-357. https://doi.org/10.1016/j.jhazmat.2018.12.006

37. McMurry JE (2010) Fundamentals of Organic Chemistry. Cengage Learning, Belmont

38. Zahiri Oghani F, Tahvildari K, Nozari M (2021) Novel antibacterial food packaging based on chitosan loaded $\mathrm{ZnO}$ nano particles prepared by green synthesis from nettle leaf extract. J Inorg Organomet Polym 31:43-54. https://doi.org/10.1007/s10904-020-01621-7

39. Pavia DL, Lampman GM, Kriz GS (2015) Introduction to Spectroscopy. Cengage Learning, Belmont

40. Sundar S, Mariappan R, Piraman S (2014) Synthesis and characterization of amine modified magnetite nanoparticles as carriers of curcumin-anticancer drug. Powder Technol 266:321-328. https://doi.org/10.1016/j.powtec.2014.06.033

41. Bhatt R, Sreedhar B, Padmaja P (2015) Adsorption of chromium from aqueous solutions using crosslinked chitosan-diethylenetriaminepentaacetic acid. Int $\mathrm{J}$ Biol Macromol 74:458-466. https://doi.org/10.1016/j.ijbiomac.2014.12.041

42. Nekouei Marnani N, Shahbazi A (2019) A novel environmental-friendly nanobiocomposite synthesis by EDTA and chitosan functionalized magnetic graphene oxide for high removal of Rhodamine B: Adsorption mechanism and separation property. Chemosphere 218:715-725. https://doi.org/10.1016/j.chemosphere.2018.11.109

43. Wu Z, Zhong H, Yuan X, Wang H, Wang L, Chen X, Zeng G, Wu Y (2014) Adsorptive removal of methylene blue by rhamnolipid-functionalized graphene oxide from wastewater. Water Res 67:330-344. https://doi.org/10.1016/j.watres.2014.09.026

44. Sing KSW, Everett DH, Haul RAW, Moscou L, Pierotti RA, Rouquerol J, Siemieniewska T (1982) Reporting physisorption data for gas/solid systems. Pure Appl Chem 54:2201-2218. https://doi.org/10.1002/9783527610044.hetcat0065

45. Myers RH, Montgomery DC, Anderson-Cook CM (2016) Response Surface Methodology: Process and Product Optimization Using Designed Experiments. Wiley, New Jersey

46. Ofomaja AE, Ho Y-S (2008) Effect of temperatures and pH on methyl violet biosorption by Mansonia wood sawdust. Bioresour Technol 99:5411-5417. https://doi.org/10.1016/j.biortech.2007.11.018

47. Konkena B, Vasudevan S (2012) Understanding aqueous dispersibility of graphene oxide and reduced graphene oxide through $\mathrm{pK}_{\mathrm{a}}$ measurements. J Phys Chem Lett 3:867-872. https://doi.org/10.1021/jz300236w

48. Su Q, Ye Q, Deng L, He Y, Cui X (2020) Prepared self-growth supported copper catalyst by recovering $\mathrm{Cu}$ (II) from wastewater using geopolymer microspheres. J Clean Prod 272:122571-122583. https://doi.org/10.1016/j.jclepro.2020.122571

49. Şentürk İ, Alzein M (2020) Adsorptive removal of basic blue 41 using pistachio shell adsorbent Performance in batch and column system. Sustain Chem Pharm 16:100254-100268. https://doi.org/10.1016/j.scp.2020.100254

50. Wang H, Zhang P, Liu J (2017) Triethylene tetramine functionalized magnetic graphene oxide chitosan composite with superior capacity for the removal of phosphate. J Chem Eng Data 62:3341-3352. https://doi.org/10.1021/acs.jced.7b00417

51. Jawad AH, Abdulhameed AS, Mastuli MS (2020) Mesoporous crosslinked chitosan-activated charcoal composite for the removal of thionine cationic dye: Comprehensive adsorption and mechanism study. J Polym Environ 28:1095-1105. https://doi.org/10.1007/s10924-020-01671-5

52. Lagergren S (1898) About the theory of so-called adsorption of soluble substances. K Sven Vetensk Akad Handl 24:1-39

53. Blanchard G, Maunaye M, Martin G (1984) Removal of heavy metals from waters by means of natural zeolites. Water Res 18:1501-1507. https://doi.org/10.1016/0043-1354(84)90124-6

54. Low MJD (1960) Kinetics of chemisorption of gases on solids. Chem Rev 60:267-312. https://doi.org/10.1021/cr60205a003 
55. Marczewski AW (2010) Application of mixed order rate equations to adsorption of methylene blue on mesoporous carbons. Appl Surf Sci 256:5145-5152. https://doi.org/10.1016/j.apsusc.2009.12.078

56. Özer A (2007) Removal of $\mathrm{Pb}(\mathrm{II})$ ions from aqueous solutions by sulphuric acid-treated wheat bran. J Hazard Mater 141:753-761. https://doi.org/10.1016/j.jhazmat.2006.07.040

57. Azizian S, Fallah RN (2010) A new empirical rate equation for adsorption kinetics at solid/solution interface. Appl Surf Sci 256:5153-5156. https://doi.org/10.1016/j.apsusc.2009.12.080

58. Haerifar M, Azizian S (2012) Fractal-like adsorption kinetics at the solid/solution interface. J Phys Chem C 116:13111-13119. https://doi.org/10.1021/jp301261h

59. Haerifar M, Azizian S (2014) Fractal-like kinetics for adsorption on heterogeneous solid surfaces. J Phys Chem C 118:1129-1134. https://doi.org/10.1021/jp4110882

60. Balakrishnan N, Voinov V, Nikulin MS (2013) Chi-Squared Goodness of Fit Tests with Applications. Elsevier, Waltham

61. Bresnahan JL, Shapiro MM (1966) A general equation and technique for the exact partitioning of chisquare contingency tables. Psychol Bull 66:252-262. https://doi.org/10.1037/h0023728

62. Largitte L, Pasquier R (2016) A review of the kinetics adsorption models and their application to the adsorption of lead by an activated carbon. Chem Eng Res Des 109:495-504. https://doi.org/10.1016/j.cherd.2016.02.006

63. Nikzad S, Amooey AA, Alinejad-Mir A (2021) High effective removal of diazinon from aqueous solutions using the magnetic tragacanth-montmorillonite nanocomposite: isotherm, kinetic, and mechanism study. Environ Sci Pollut Res 28:20426-20439. https://doi.org/10.1007/s11356-020-12238-1

64. Xia F, Yang H, Li L, Ren Y, Shi D, Chai H, Ai H, He Q, Gu L (2020) Enhanced nitrate adsorption by using cetyltrimethylammonium chloride pre-loaded activated carbon. Environ Technol 41:3562-3572. https://doi.org/10.1080/09593330.2019.1615133

65. Ofomaja AE (2010) Intraparticle diffusion process for lead(II) biosorption onto mansonia wood sawdust. Bioresour Technol 101:5868-5876. https://doi.org/10.1016/j.biortech.2010.03.033

66. Omidi S, Kakanejadifard A (2018) Eco-friendly synthesis of graphene-chitosan composite hydrogel as efficient adsorbent for Congo red. RSC Adv 8:12179-12189. https://doi.org/10.1039/c8ra00510a

67. Langmuir I (1918) The adsorption of gases on plane surfaces of glass, mica and platinum. J Am Chem Soc 40:1361-1403. https://doi.org/10.1021/ja02242a004

68. Freundlich HMF (1906) Over the adsorption in solution. J Phys Chem 57:385-471

69. Temkin M, Pyzhev V (1940) Kinetics of ammonia synthesis on promoted iron catalysts. Acta Physicochim URSS 12:327-356

70. Azizian S, Eris S, Wilson LD (2018) Re-evaluation of the century-old Langmuir isotherm for modeling adsorption phenomena in solution. Chem Phys 513:99-104. https://doi.org/10.1016/j.chemphys.2018.06.022

71. Redlich O, Peterson DL (1959) A useful adsorption isotherm. J Phys Chem 63:1024-1030. https://doi.org/10.1021/j150576a611

72. Toth J (1971) State equation of the solid-gas interface layers. Acta Chim Acad Sci Hung 69:311-328

73. Yao C (2000) Extended and improved Langmuir equation for correlating adsorption equilibrium data. Sep Purif Technol 19:237-242. https://doi.org/10.1016/S1383-5866(00)00060-5

74. Sips R (1948) On the structure of a catalyst surface. J Chem Phys 16:490-495. https://doi.org/10.1063/1.1746922

75. Saravanan P, Josephraj J, Thillainayagam BP, Ravindiran G (2021) Evaluation of the adsorptive removal of cationic dyes by greening biochar derived from agricultural bio-waste of rice husk. Biomass Convers Biorefin. https://doi.org/10.1007/s13399-021-01415-y

76. El-Gendy NS, El-Salamony RA, Amr SSA, Nassar HN (2015) Statistical optimization of Basic Blue 41 dye biosorption by saccharomyces cerevisiae spent waste biomass and photo-catalytic regeneration using acid $\mathrm{TiO}_{2}$ hydrosol. J Water Process Eng 6:193-202. https://doi.org/10.1016/j.jwpe.2015.04.007

77. Nouri L, Hemidouche S, Boudjemaa A, Kaouah F, Sadaoui Z, Bachari K (2020) Elaboration and characterization of photobiocomposite beads, based on titanium (IV) oxide and sodium alginate biopolymer, for basic blue 41 adsorption/photocatalytic degradation. Int J Biol Macromol 151:66-84. https://doi.org/10.1016/j.ijbiomac.2020.02.159

78. Humelnicu I, Băiceanu A, Ignat ME, Dulman V (2017) The removal of basic blue 41 textile dye from aqueous solution by adsorption onto natural zeolitic tuff: Kinetics and thermodynamics. Process Saf Environ Prot 105:274-287. https://doi.org/10.1016/j.psep.2016.11.016 
Figures
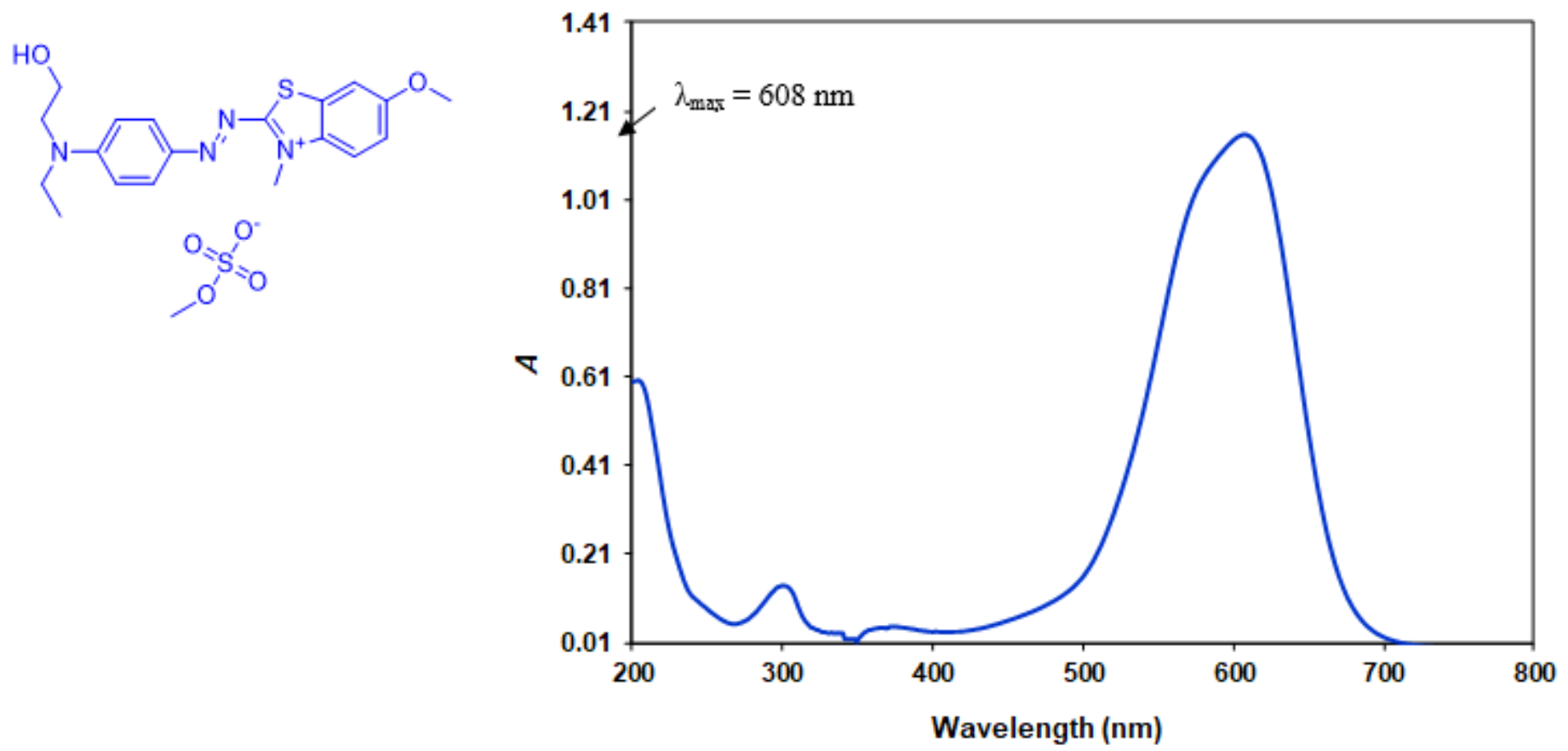

Figure 1

Structure and UV-Vis absorption spectrum of basic blue 41 at concentration of $10.0 \mathrm{mg} \cdot \mathrm{L}-1$ and $\mathrm{pH}$ of 6.5

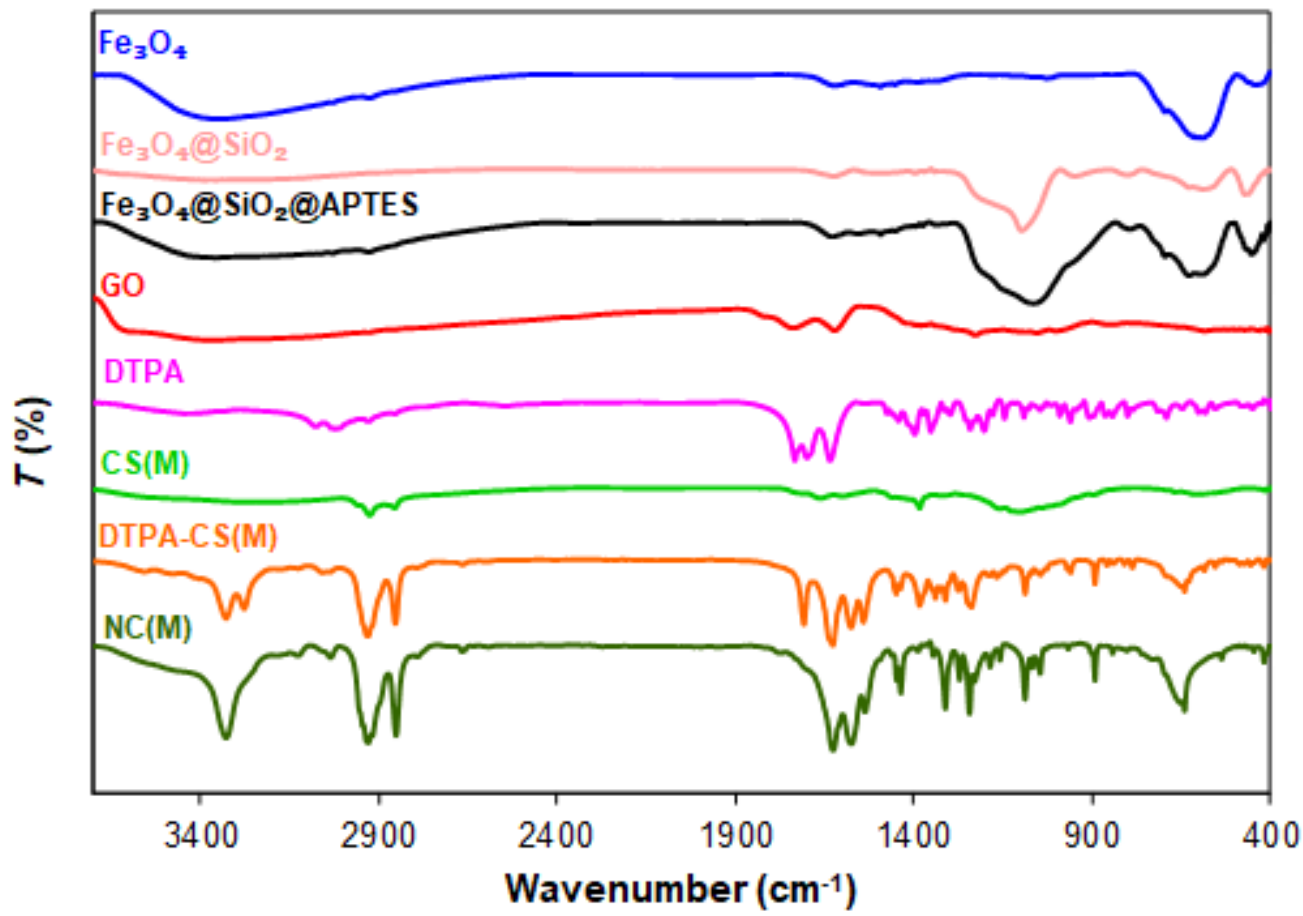

Figure 2 
FT-IR spectra of Fe304, Fe304@SiO2, Fe304@SiO2@APTES, GO, DTPA, CS(M), DTPA-CS(M), and NC(M)

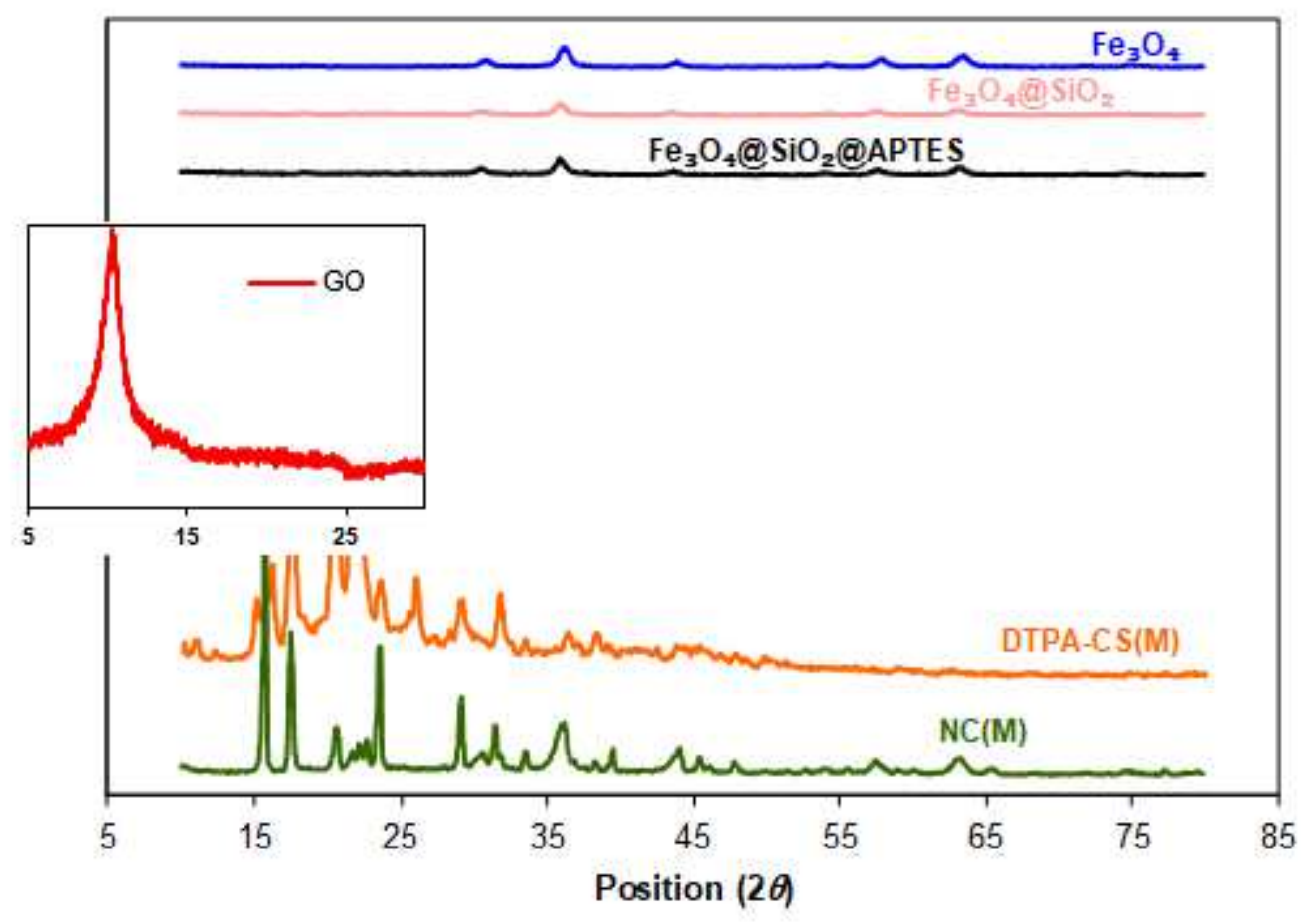

Figure 3

XRD patterns of Fe304,Fe304@SiO2, Fe304@Si02@APTES, GO, DTPA-CS(M), and NC(M)
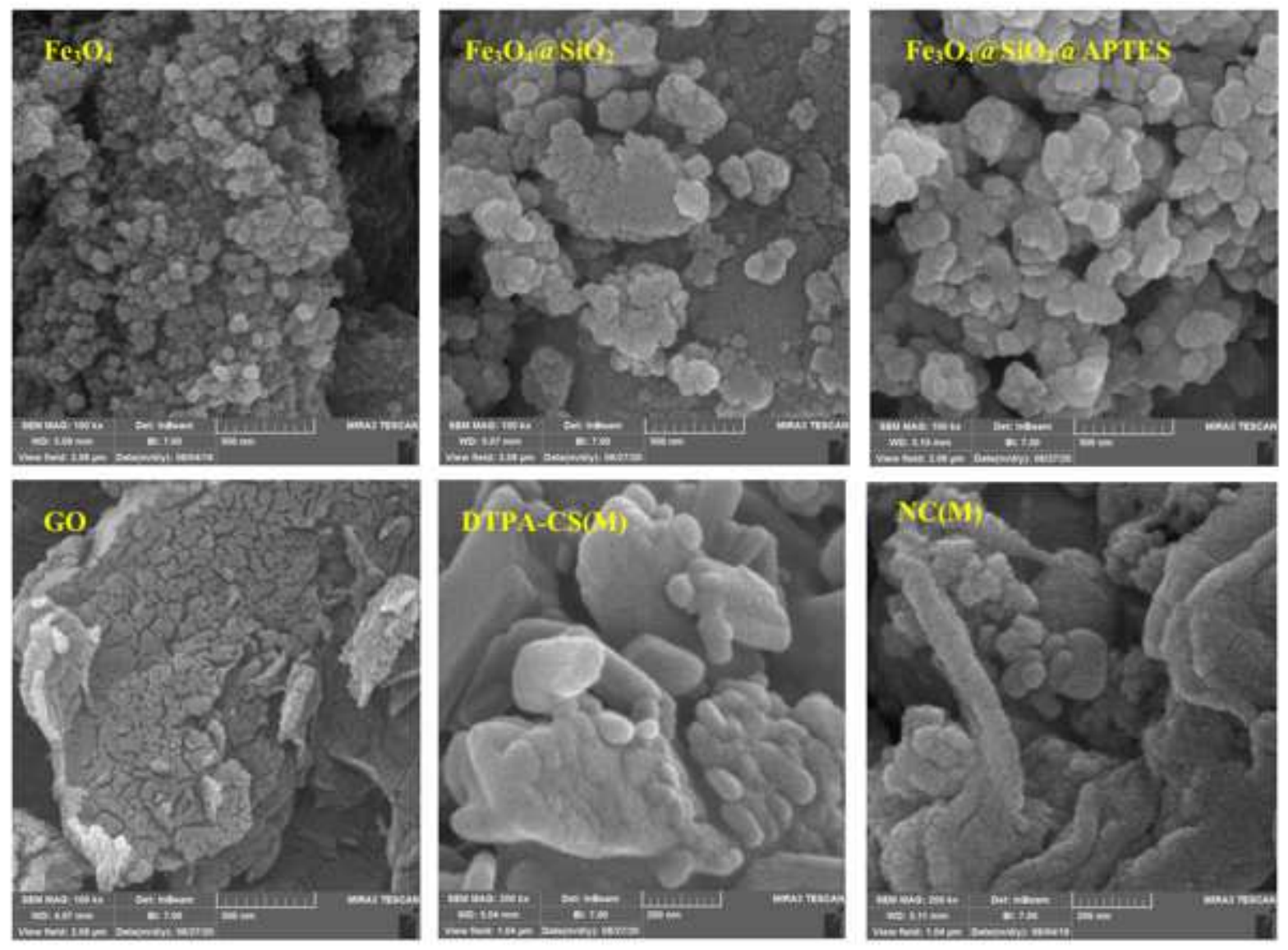
Figure 4

FESEM images of Fe304, Fe304@SiO2, Fe304@SiO2@APTES, GO, DTPA-CS(M), and NC(M)
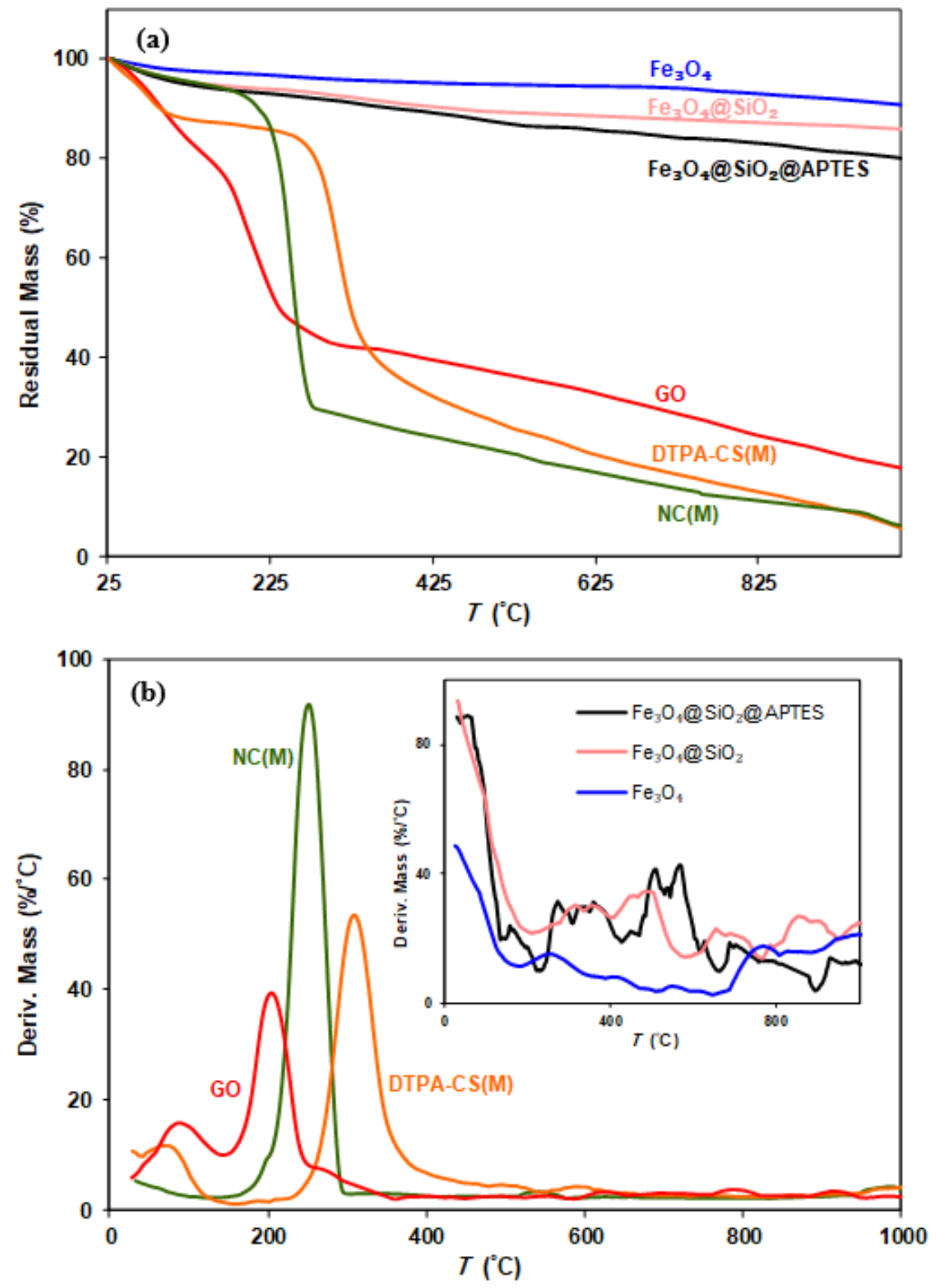

Figure 5

(a) TGA and (b) DTG curves of Fe304, Fe304@Si02, Fe304@Si02@APTES, GO, DTPA-CS(M), and NC(M) 


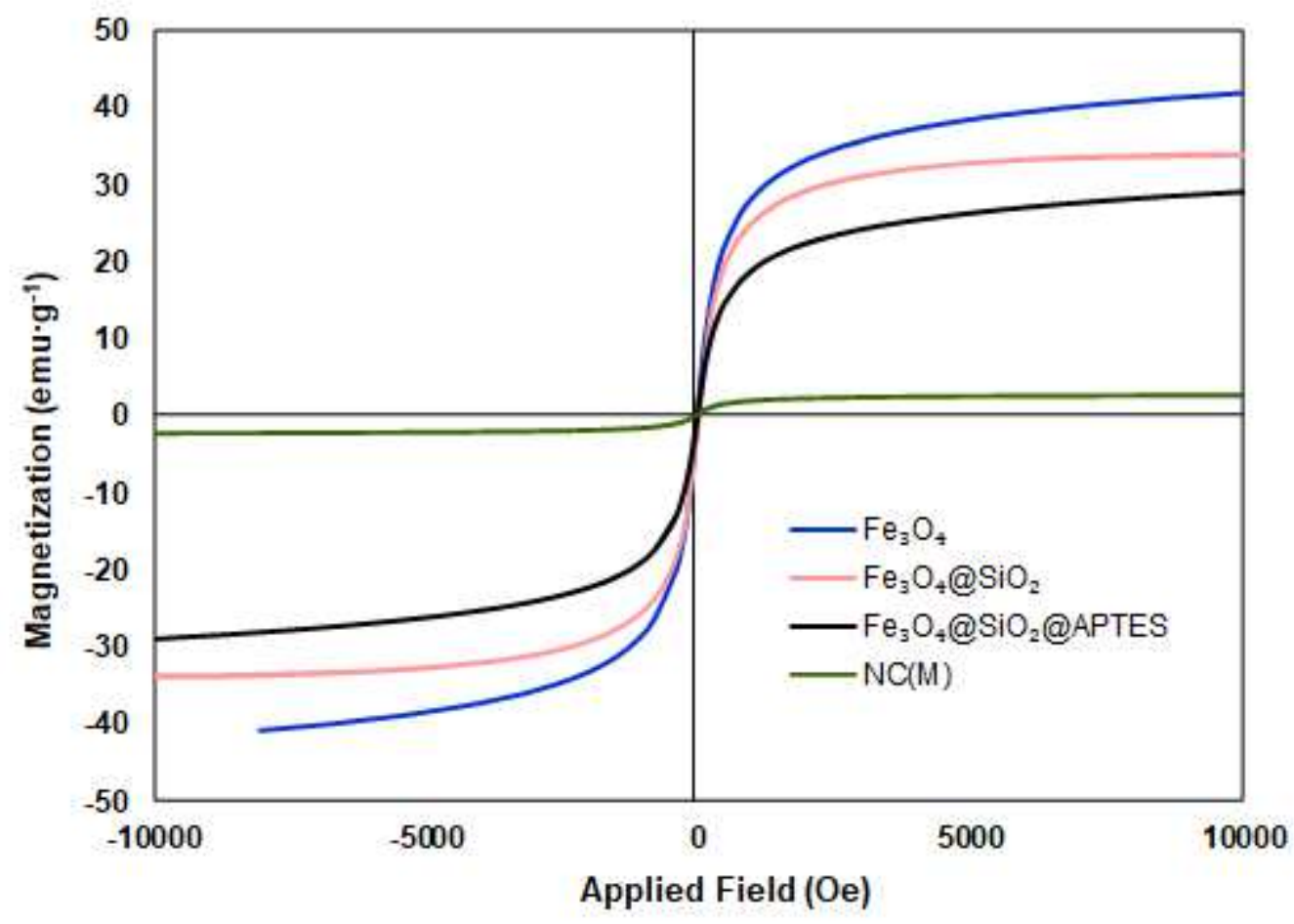

Figure 6

Magnetization measurements for Fe304,Fe304@SiO2, Fe304@SiO2@APTES and NC(M)

(a)

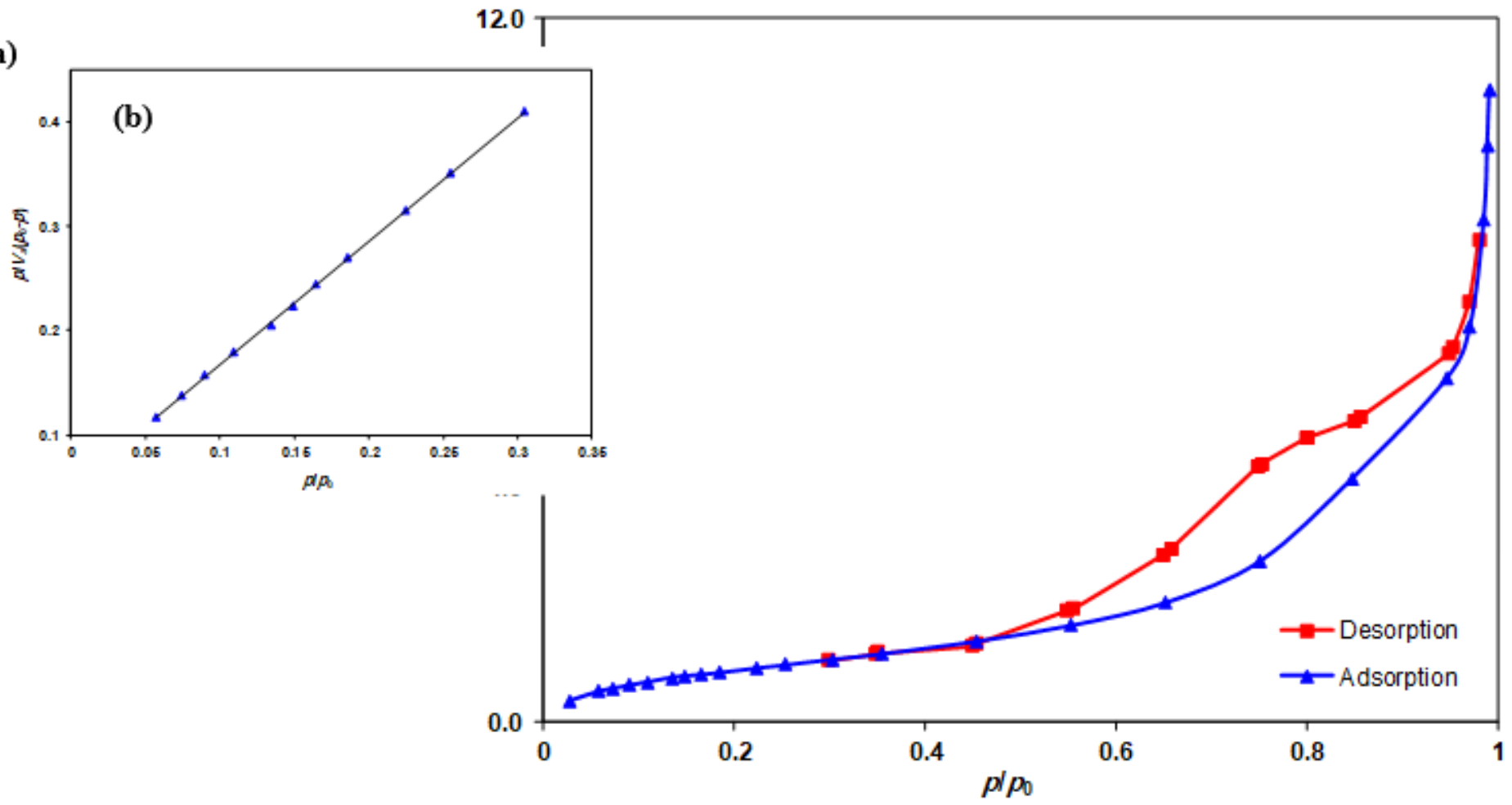

Figure 7

(a) N2 adsorption/desorption isotherm at $77 \mathrm{~K}$, (b) BET plot of NC(M) 


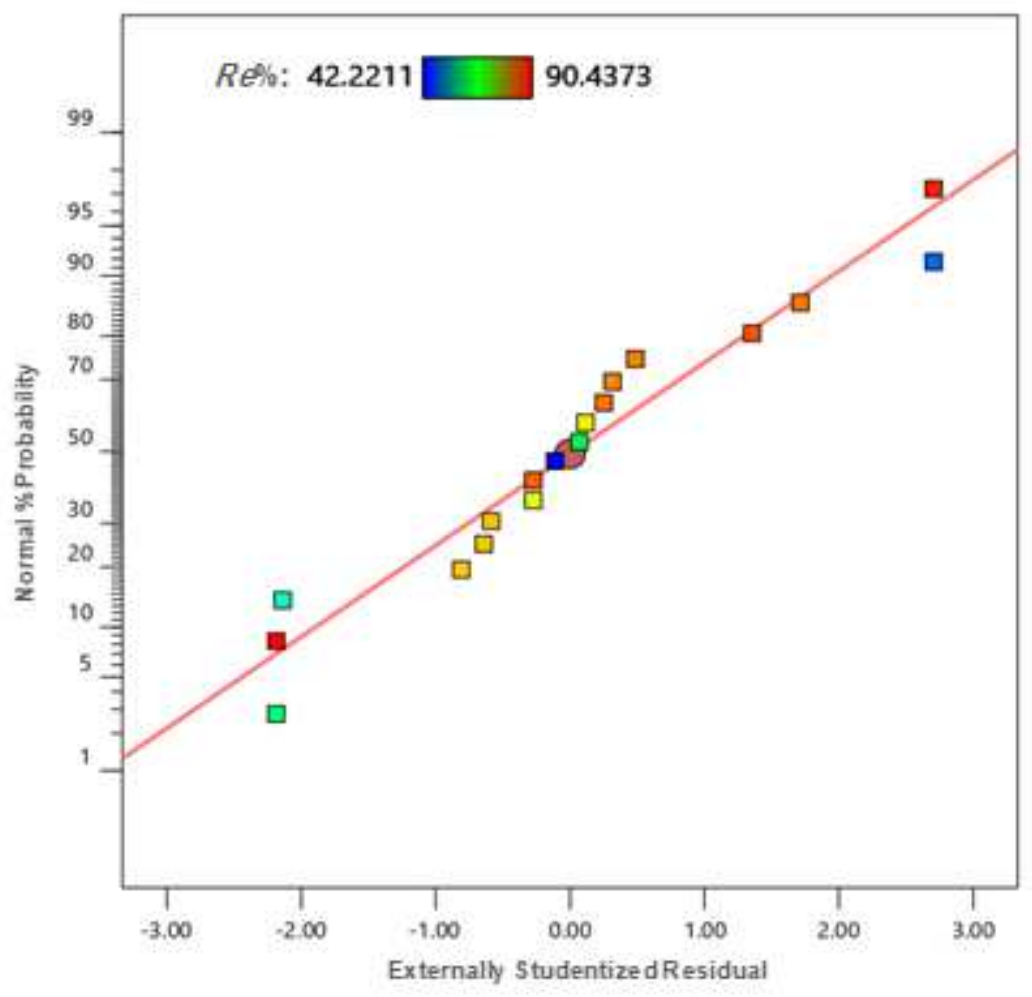

Figure 8

Normal plot of residuals

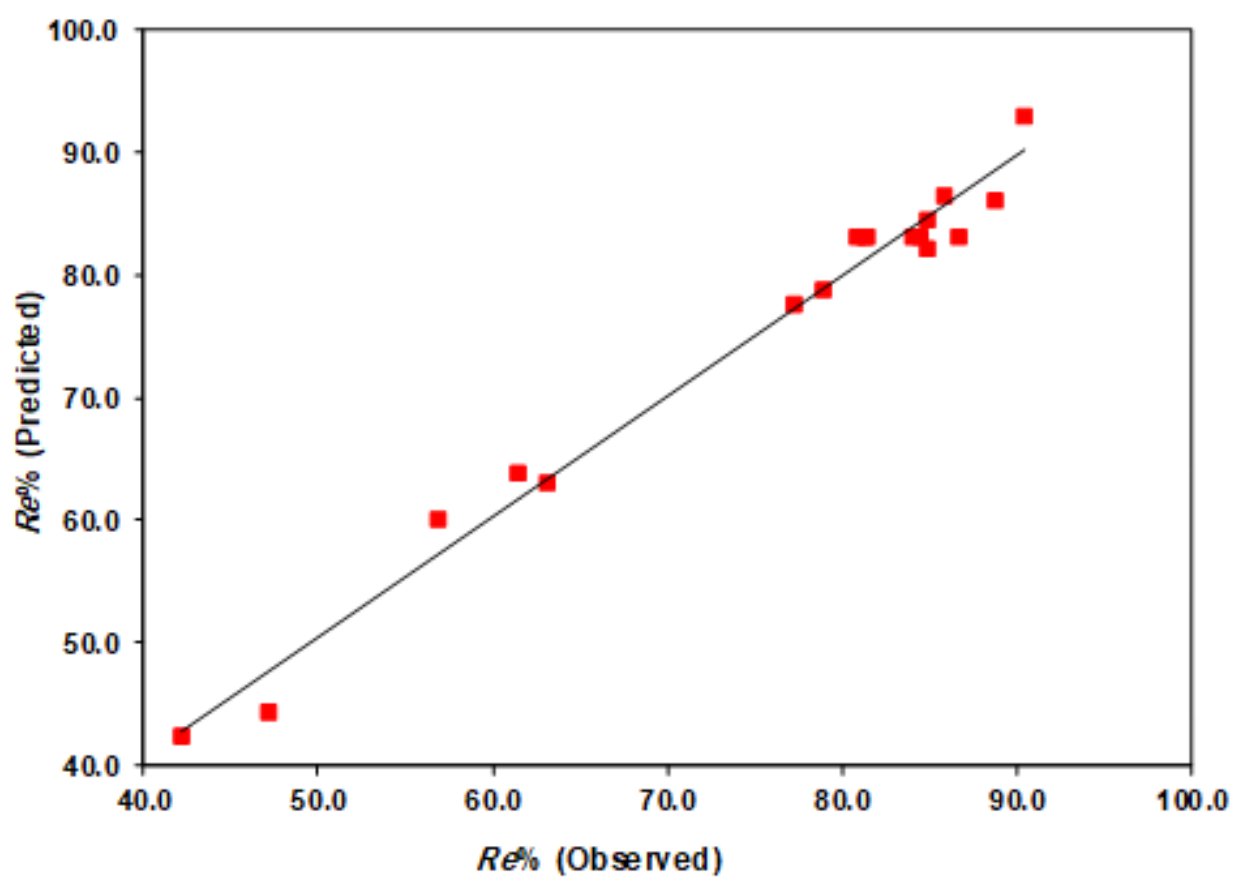

Figure 9

Plot of predicted response versus observed response 


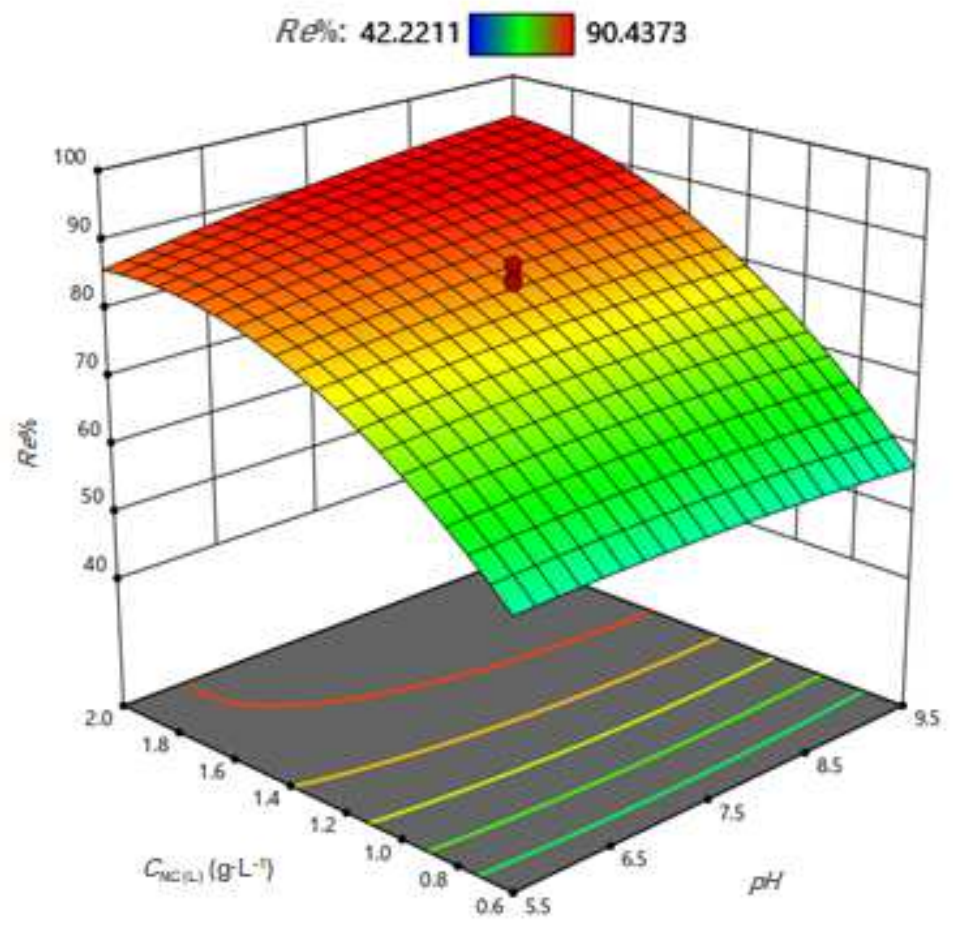

\section{Figure 10}

Response surface plot for percentage of dye removal as a function of nanocomposite concentration and initial $\mathrm{pH}$ at temperature of $43.0^{\circ} \mathrm{C}$

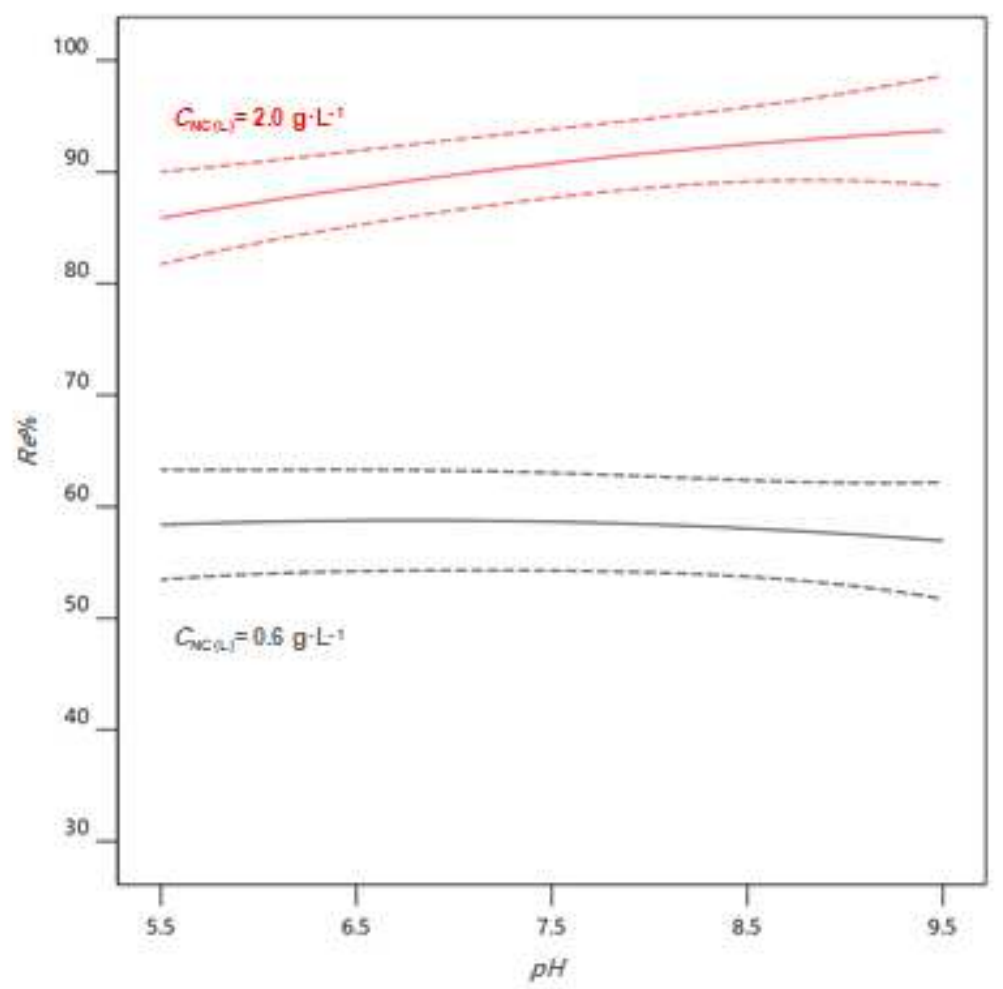

Figure 11 
Percentage of dye removal versus $\mathrm{pH}$ at two different nanocomposite concentrations with $95 \%$ confidence interval and temperature of $43.0^{\circ} \mathrm{C}$

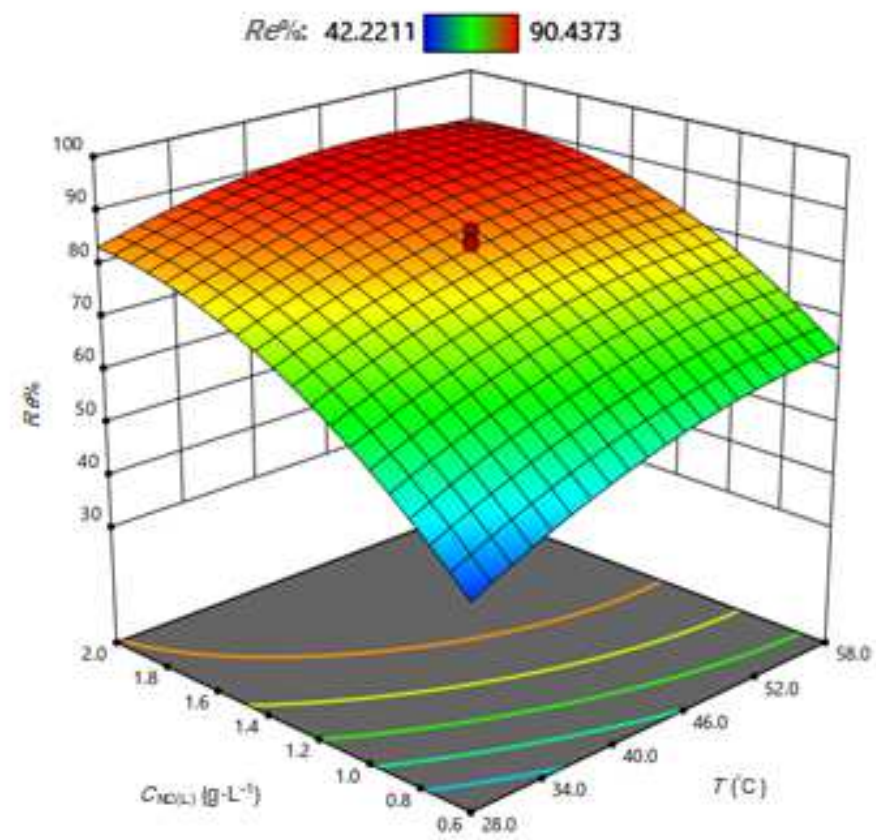

Figure 12

Response surface plot for percentage of dye removal as a function of nanocomposite concentration and temperature at $\mathrm{pH}$ of 7.50

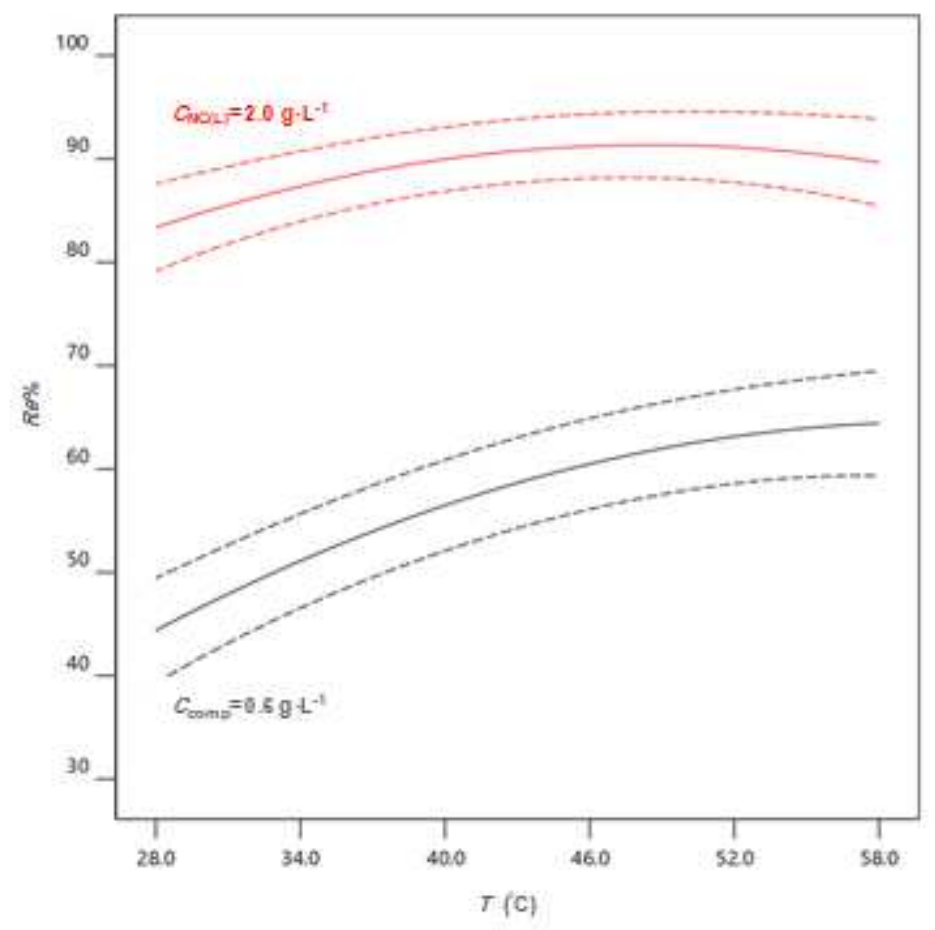

Figure 13 
Percentage of dye removal versus temperature at two different nanocomposite concentrations with $95 \%$ confidence interval and $\mathrm{pH}$ of 7.50

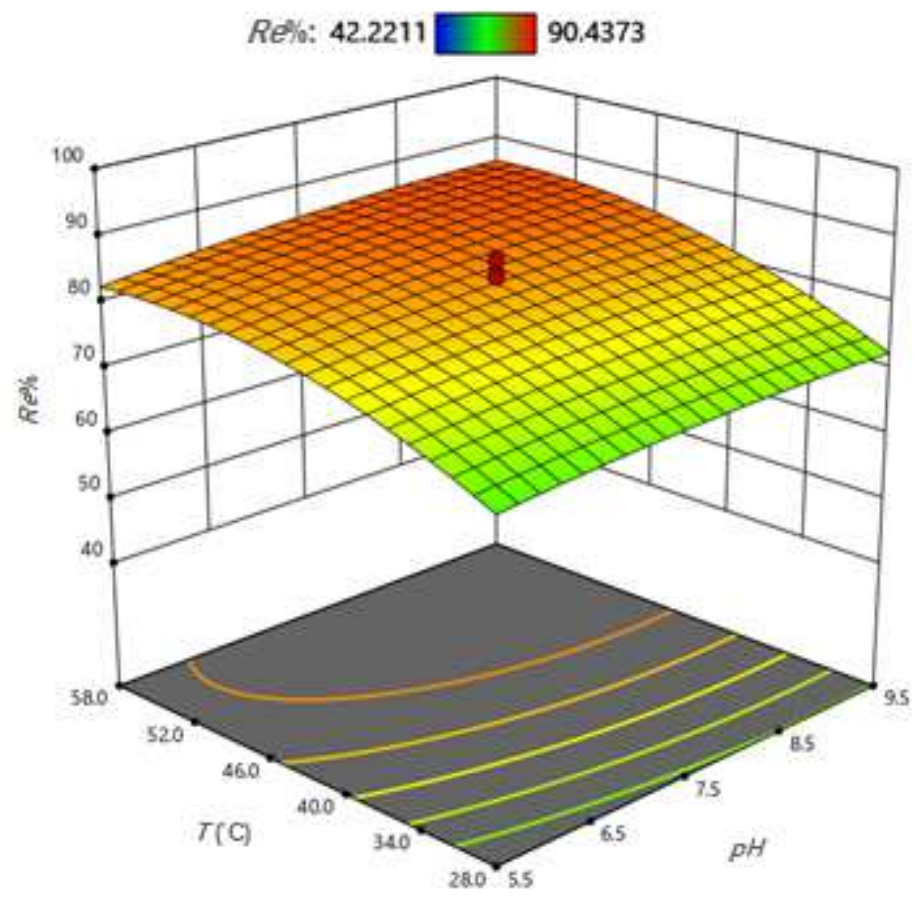

\section{Figure 14}

Response surface plot for percentage of dye removal as a function of $\mathrm{pH}$ and temperature at nanocomposite concentration of $1.30 \mathrm{~g} \cdot \mathrm{L}-1$

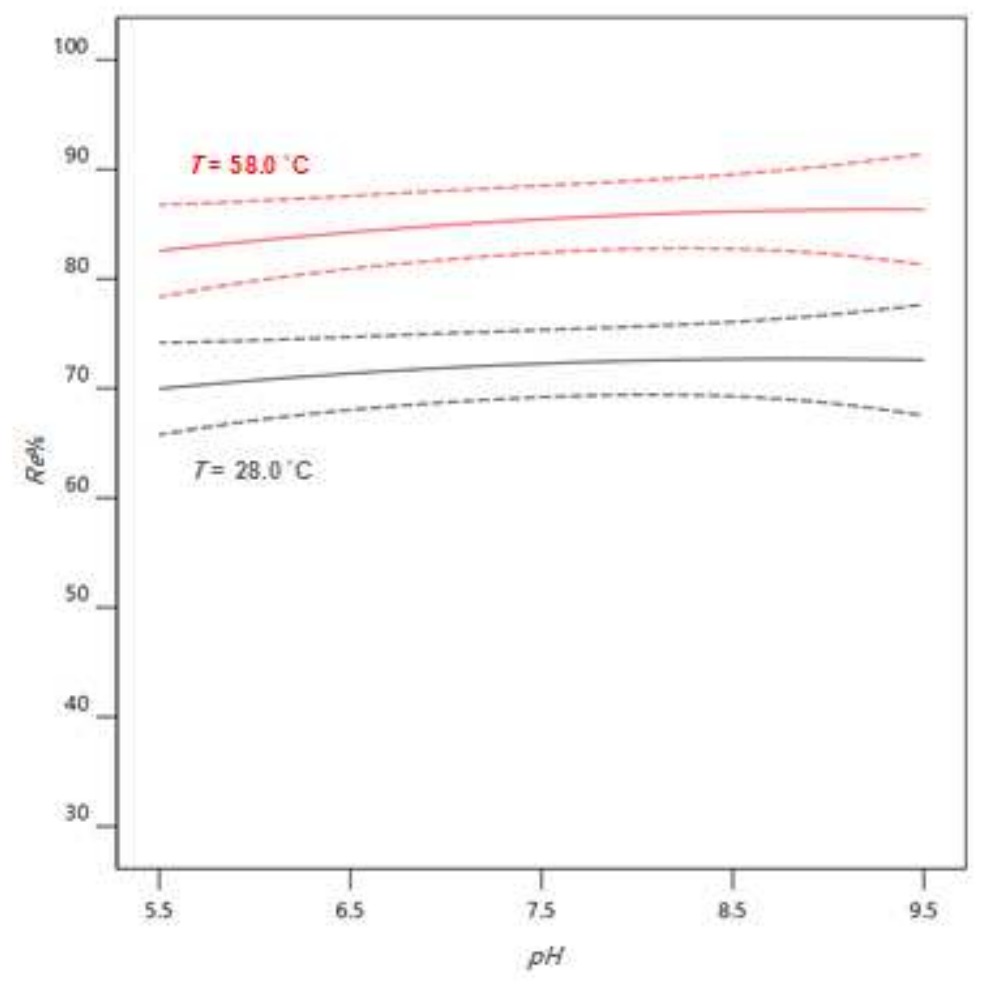

Figure 15 
Percentage of dye removal versus $\mathrm{pH}$ at two temperatures with $95 \%$ confidence interval and nanocomposite concentration of $1.30 \mathrm{~g} \cdot \mathrm{L}-1$

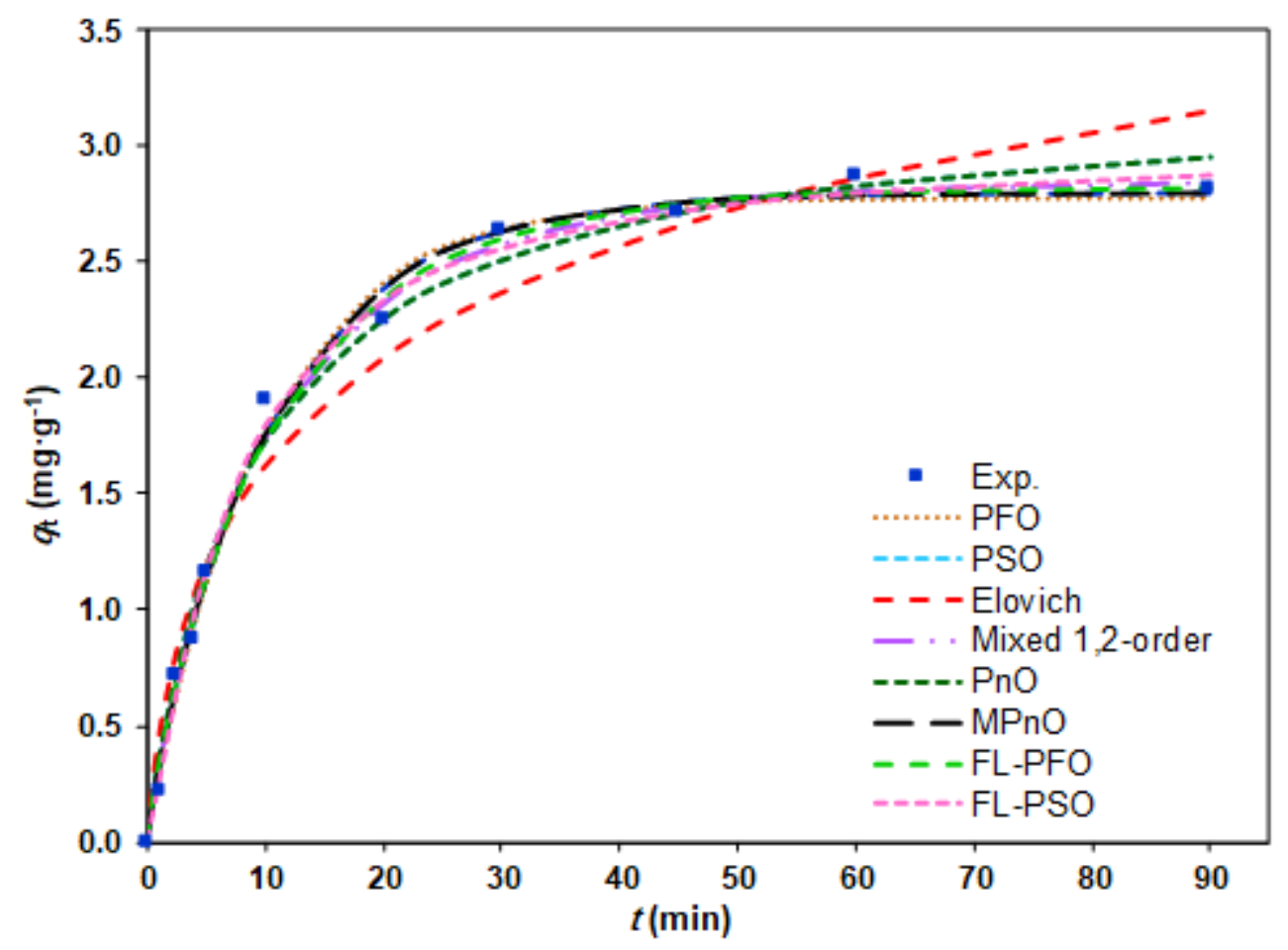

\section{Figure 16}

Experimental and fitted kinetics data for adsorption of BB41 with concentration of $8.0 \mathrm{mg} \cdot \mathrm{L}-1$ under optimum conditions

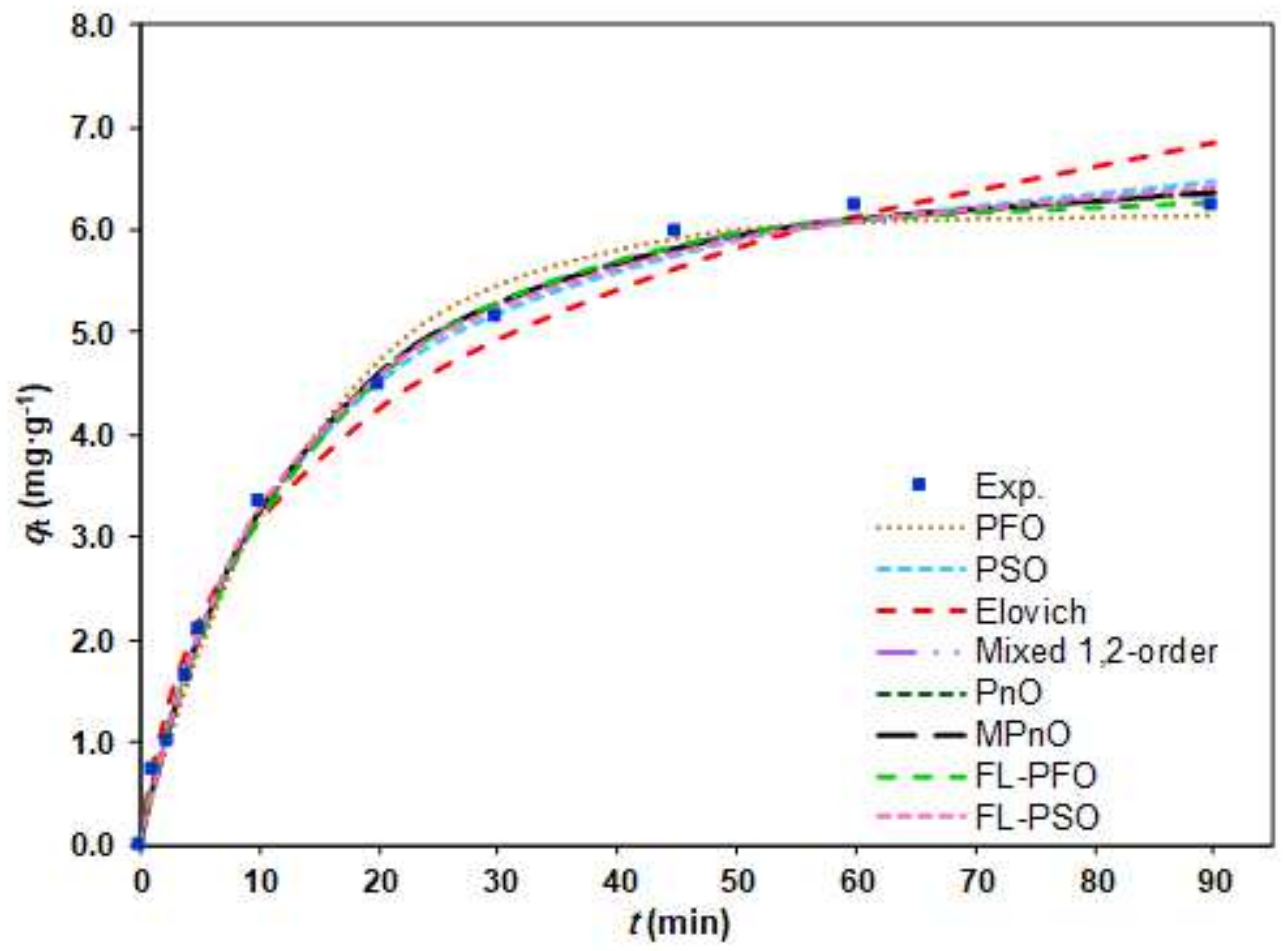


Figure 17

Experimental and fitted kinetics data for adsorption of BB41 with concentration of $15.0 \mathrm{mg} \cdot \mathrm{L}-1$ under optimum conditions

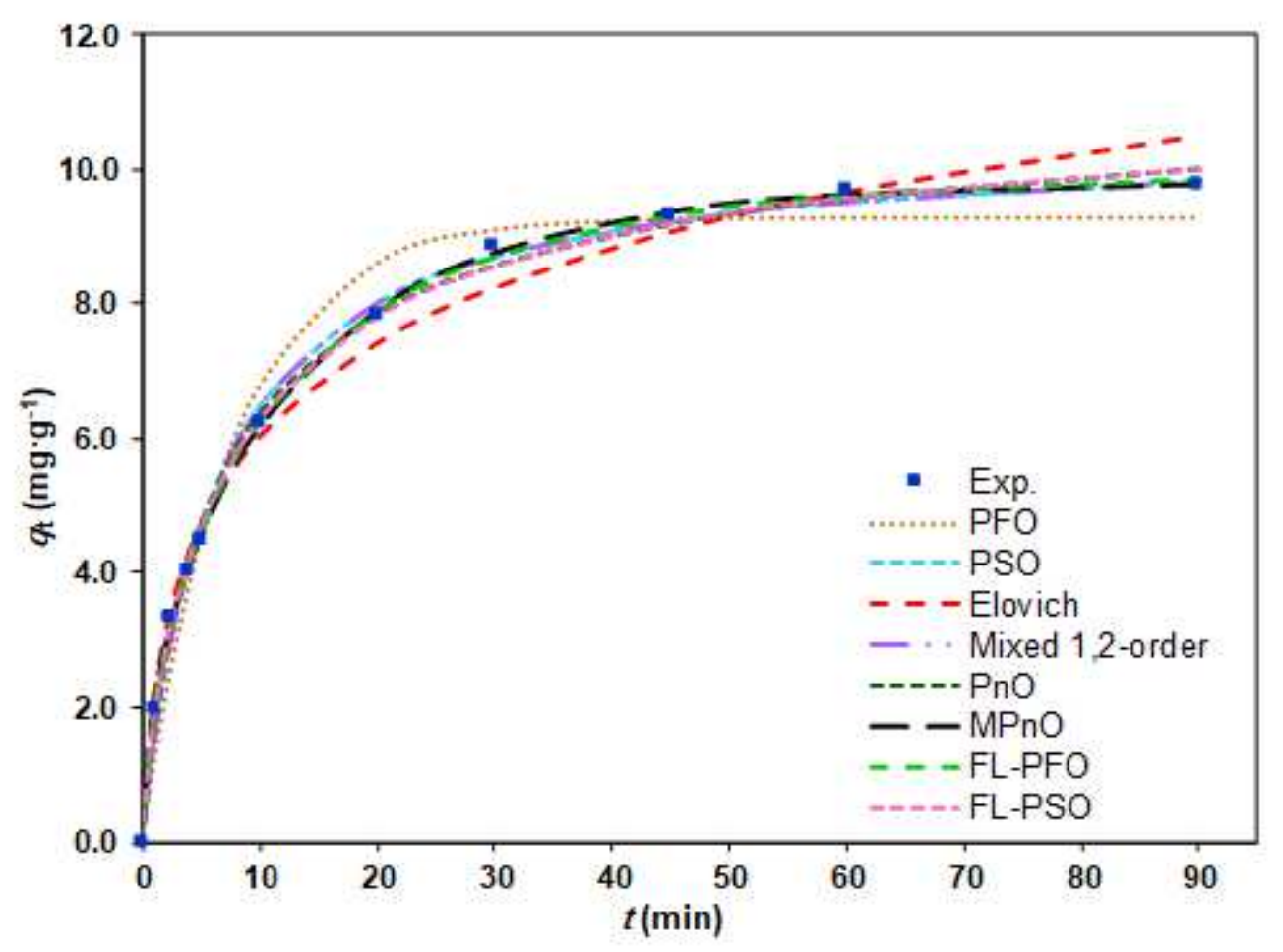

\section{Figure 18}

Experimental and fitted kinetics data for adsorption of BB41 with concentration of $30.0 \mathrm{mg} \cdot \mathrm{L}-1$ under optimum conditions

Stage (I)

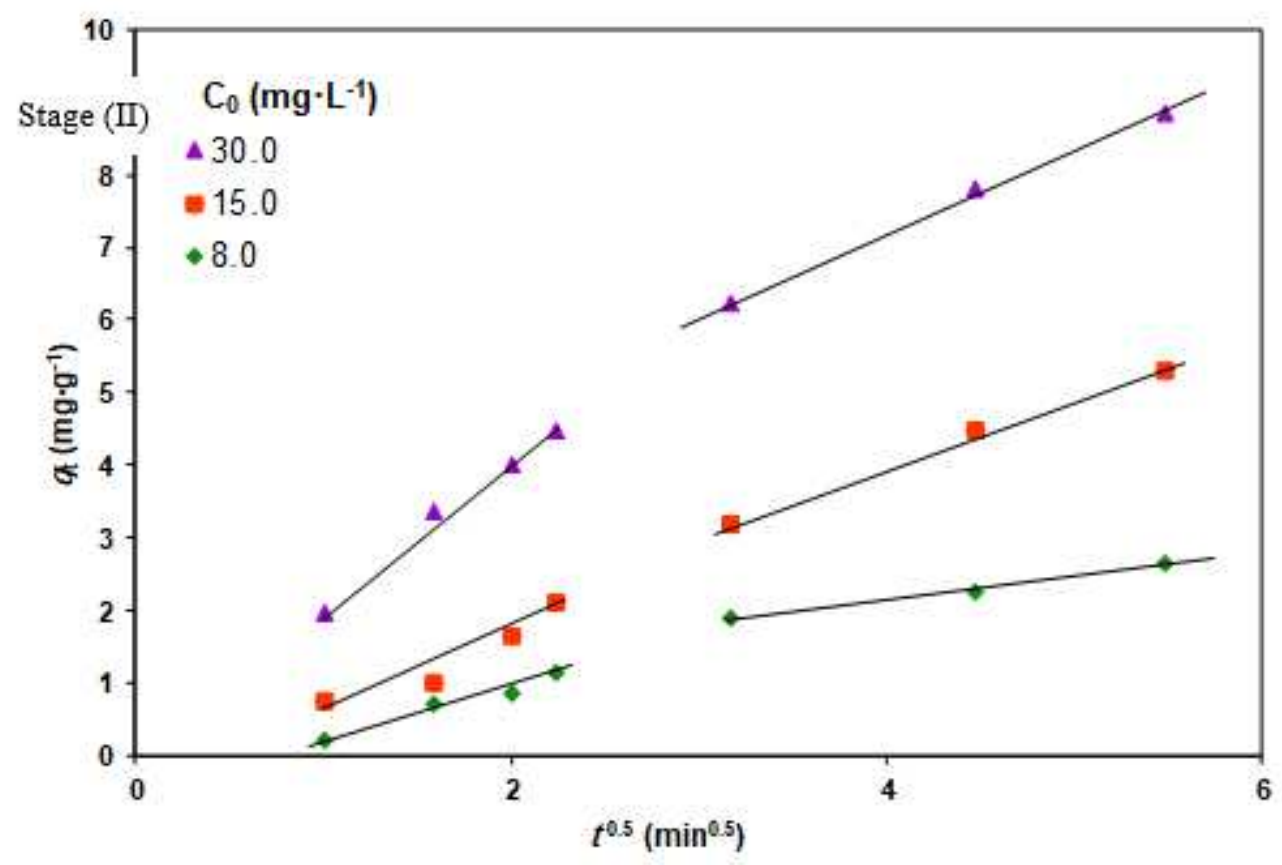


Figure 19

Intra-particle diffusion plot for BB41 adsorption at different concentrations under optimum conditions

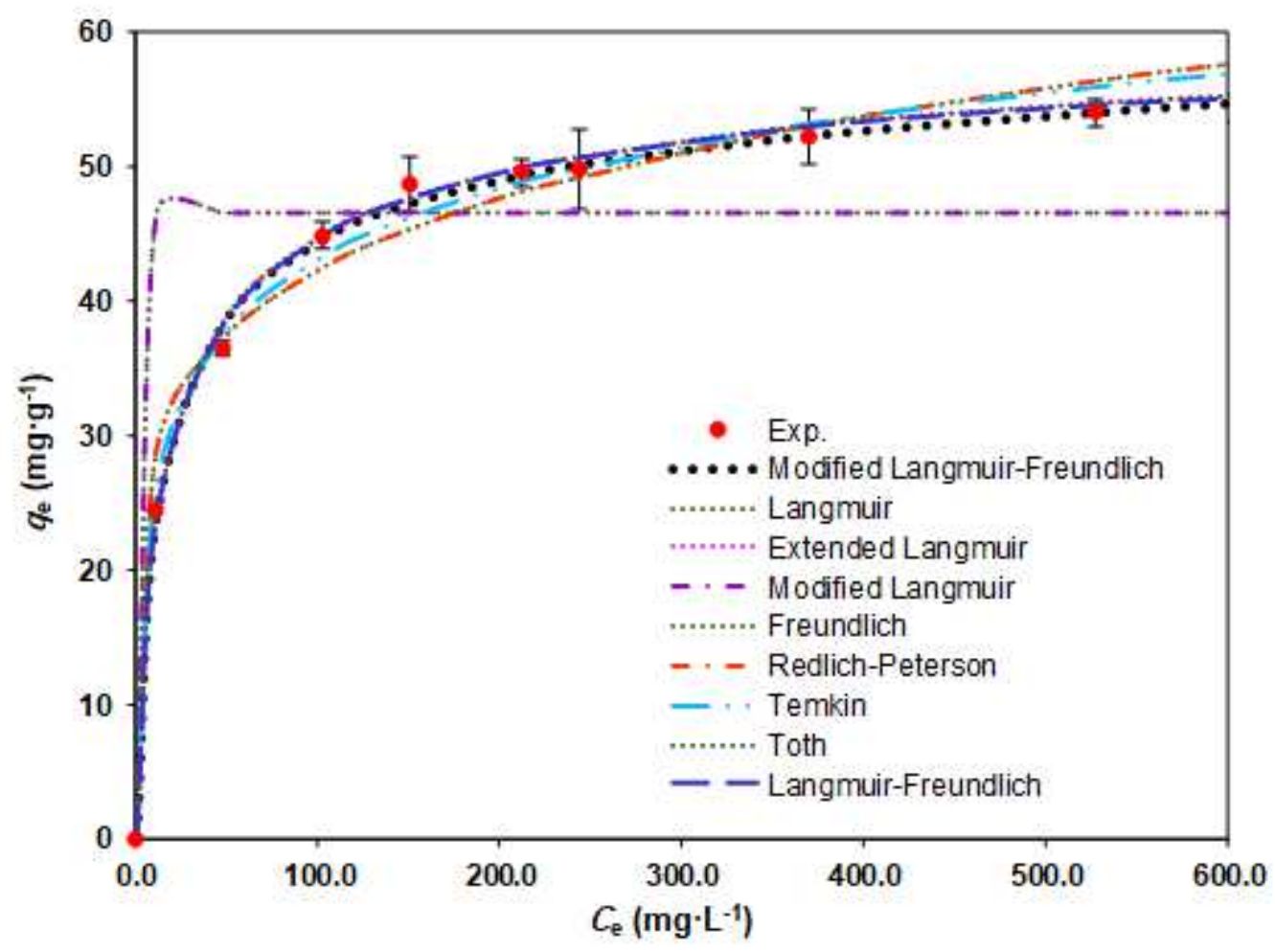

Figure 20

Adsorption isotherms for adsorption of BB41 under optimum conditions

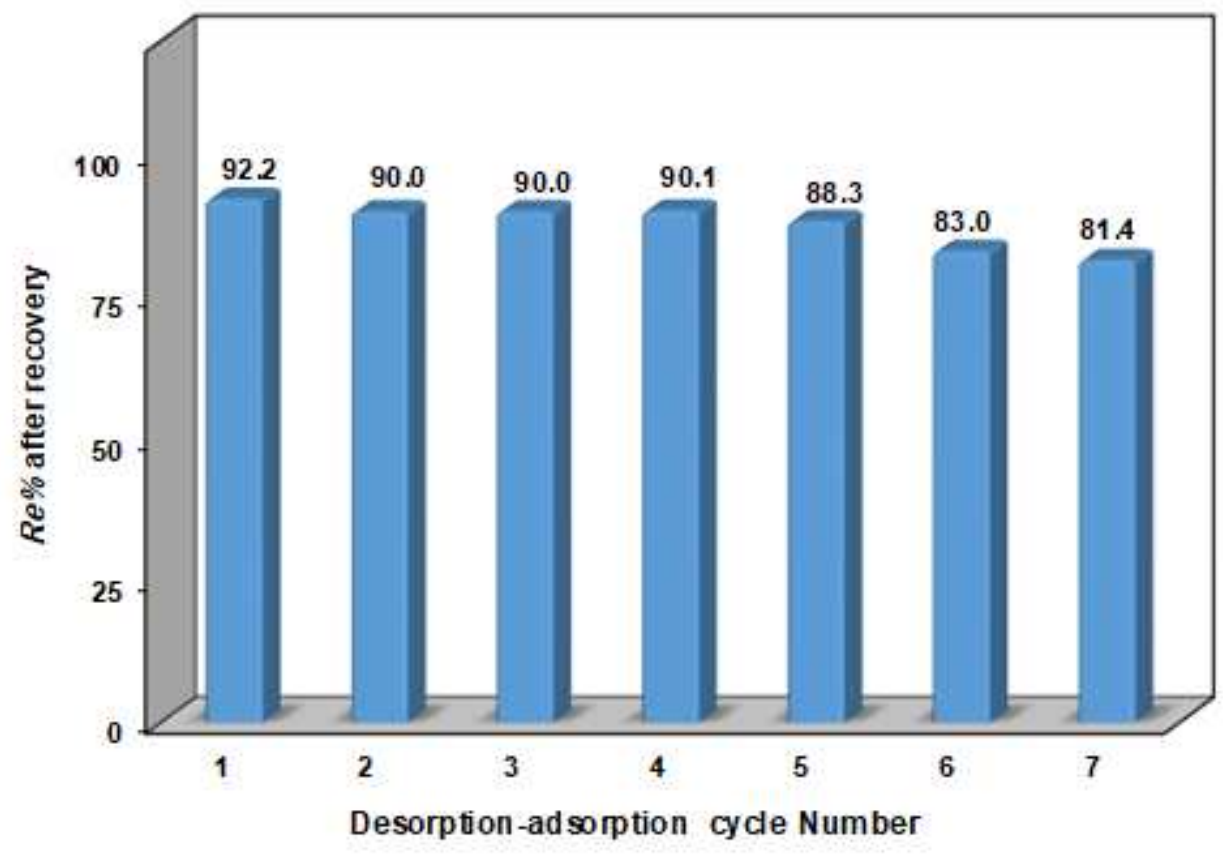

Figure 21 
Percentage of dye removal after recovery

\section{Supplementary Files}

This is a list of supplementary files associated with this preprint. Click to download.

- SupplementaryInformation.docx

- GraphicalAbstract.png 